\title{
Human capital in Republican and New China: regional and long-term trends
}

Bas van Leeuwen*, Jieli van Leeuwen-Li, and and Peter Foldvari ${ }^{1}$

\begin{abstract}
In recent decades it has been debated whether China's growth performance is primarily driven by capital accumulation (more inputs) or rather by an increase in Total Factor Productivity (TFP) growth (better technology and institutions). The answer to this question may offer a glimpse into the future trends of China-s economic growth. If the perspiration factors are dominant, one should expect a slowdown in the growth of the Chinese economy in accordance with the traditional Solow model. If, however, TFP growth drives per capita GDP growth, one can expect a strong convergence of China toward the technological frontier.

In this paper we combine historical, long-term analysis with quantitative methods to find out whether the effect of (both human- and physical) capital and TFP on growth changed over the last 90 years. While partly relying on existing data, lack of information required us to estimate a new dataset on human capital for the provinces of China between 1922 and 2010 which allows us to decompose the observed economic growth into accumulation driven and TFP driven parts. We find that general technological development improved steadily over the course of the 1990s and 2000s.
\end{abstract}

Keywords: China, economic development, human capital, technology

JEL codes: N15, O11, P23

\footnotetext{
${ }^{1}$ Bas van Leeuwen (corresponding author), International Institute of Social History, Cruquiusweg 31, 1019AT, Amsterdam, the Netherlands bas.vanleeuwen1@googlemail.com. Jieli van Leeuwen-Li, International Institute of Social History, Cruquiusweg 31, 1019AT, Amsterdam, the Netherlands, jielilivanleeuwen@ gmail.com. Peter Foldvari, International Institute of Social History, Cruquiusweg 31, 1019AT, Amsterdam, the Netherlands P.Foldvari1@uu.nl. We would like to thank three anonymous referees for their comments, which allowed us to significantly improve this paper.

The research leading to these results received funding from the European Research Council under the European Union's Horizon 2020 Programme / ERC-StG 637695 - HinDI, as part of the project "The historical dynamics of industrialization in Northwestern Europe and China ca. 1800-2010: a regional interpretation".
} 


\section{Introduction}

China has recently experienced remarkable economic growth. Between 2000 and 2008, China's per capita growth rate ranked eighth worldwide. At the same time, however, its educational rank -according to data published by Barro and Lee (2010) -- was seventy-ninth, not far from that of countries like Gabon, Iran and Mongolia, while, according to the Extended Penn World Tables, China ranked seventy-third in terms of per capita physical capital, in the same range as countries such as the Dominican Republic, Venezuela and Romania (Marquetti and Foley 2011).

At first sight, these numbers suggest that during the period under study China's economic growth was not driven primarily by the accumulation of human- and physical capital, , since the level of the factors of production was not substantially higher than the worldwide average. Economic growth must therefore have been driven by technological and institutional development (Total Factor Productivity - TFP) growth (the inspiration factor -- a term coined by Krugman in 1994 as opposed to "perspiration" factor with which he meant capital accumulation). This scenario, however, fails to find corroboration in the current literature. Thanks to improved measures of physical capital, several studies (e.g., Chow 1993) have found that physical capital growth has contributed significantly (roughly 50 per cent) to China's GDP per capita growth but that TFP growth has been insignificant at best, and may in fact have been negative.

If these latter empirical results are correct, we can expect a future decline in China's economic growth, since the rapid growth of the perspiration factors cannot be sustained in the long run because of diminishing returns on the factors of production (Young 1995; Krugman 1997). Collins and Bosworth (1996), however, demur, foreseeing an increase over time in the significance of inspiration (TFP growth). ${ }^{2}$ Some studies have indeed argued that standard TFP analysis indicates such an increase in TFP growth; for instance, not only Wang and Yao (2003) but also Li (2009) find that TFP growth increased considerably during the late 1990s.

Most studies however either neglect the accumulation of human capital or use proxies like the average years of education at best. As Van Leeuwen and Foldvari (2011) argue, however, using average years of education in growth regressions is fraught with problems, largely because it exclude the quality of human capital thus resulting in downward biased estimates of the contribution of human capital to economic growth and an overestimate of the TFP growth. Zhu (2012), for example, uses average years of education as a proxy of human capital, and finds that human capital accumulation actually mattered much less in the economic growth in the 1978-2007 period than between 1952 and 1978 and attributed the observed rapid economic growth at the end

2 Bosworth and Collins (1996: 15*) find that TFP growth contributed about 50 per cent to over-all growth between 1960 and 1994. 
of the $20^{\text {th }}$ and start of the $21^{\text {st }}$ century largely to TFP growth. While China can be seen as a special case, it is still strange that in a phase where human capital as a driver of innovations is expected to matter more than before, the finding that it was just the reverse. Indeed, after trying to correct for the quality of human capital, Whalley and Zhao (2010) find a significant effect of human capital combined with a negative TFP growth for the late 1990s, even though there are significant differences at the provincial level. For example, Li (2009, 219), having estimated TFP growth for four main regions, concludes that TFP growth was highest in the Eastern provinces. ${ }^{3}$

From these discussions it appears that the main problems in determining the effect of capital accumulation (perspiration) and technology (TFP, or inspiration) o economic growth can be found in, on the one hand, creating a quality based measure of human capital and, on the other hand, allowing for regional differences. Therefore, in this paper we combine the existing regional GDP and physical-capital estimates with a new dataset on human capital, calculated at the provincial level and going back to the 1920s to analyze the effects of factor accumulation and TFP on economic growth. We find that including the contribution of quality corrected human capital to economic growth leaves us with a negative growth of TFP. This would imply that the observed economic growth in China was due to factor accumulation and hence we should expect a slowdown or even a cease of future economic growth. This is not the entire story though as TFP contains both technology and institutions. If we define the institutional part of TFP roughly as "technical efficiency" (i.e. efficiency with which the factors of production are transformed into real income), the residual can be attributed to the direct effect of technology (i.e. expansion of the technological frontier). Obviously the former depends on the factor endowment of a particular region, and the relative ratio of labor and different forms of capital. Separating this technical efficiency from general technological development can be done using the different provincial contributions of factors of production to economic growth. Having corrected for provincial differences in technical efficiency, we find evidence of a positive rate of general technological development, especially from the 1990s onwards.

The structure of this paper is as follows: In the next section, we outline our estimation of the cost-based measure of human capital by province within present-day borders, which is a slightly modified version of the measure suggested by Judson (2002). Since the factors of production may differ by province with respect to their technical efficiency, in Section 3 we analyze the spread of human and physical capital through China. In Section 4 we analyze the development of TFP, technical efficiency and general technical development. We end with a brief conclusion.

3 Alternatively, Bao et al. (2002) argue that geographical factors account for much of the higher growth in the coastal provinces 


\section{A new dataset on provincial human capital in China, 1922-2010}

Whereas various datasets exist on physical capital and GDP, human capital data are less easily available. Even though some growth accounting studies make use of average years of education in recent decades, few studies include the value of human capital ${ }^{4}$ in their estimates, and of those that do, none provide estimates by province. Indeed, there have been several studies of average years of education among China's population: Barro and Lee (1993, 1996, 2001, 2010) report the average number of years of schooling for every fifth year beginning with 1950 in China, and Cohen and Soto (2007) do likewise for every tenth year between 1960 and 2010. Wang and Yao (2002) estimate annual series between 1952 and 1999, but, for lack of data they base their estimation on the Indian census of 1951 in combination with the annual number of graduates by educational level. $\mathrm{Li}$ (2009) estimates average years of education for several regions in China during the past few decades. However, long-run, historical estimates similar to those of Morrisson and Murtin (2009) were not yet been available for China. Although Morrisson and Murtin do make one conjecture concerning early-twentieth-century China in their paper, they argue that since 'there do not exist any satisfactory historical statistics $[\ldots]$, the data $[\ldots]$ serve only an illustrative purpose $[\ldots]$ and shall be taken with caution' (29). This may also be the reason that until now there have been no estimates of long-run human capital at the provincial level.

This lack of data becomes even more worrying when one seeks to measure human capital by its value, which is a crucial aspect of growth accounting. Since individuals' abilities and skills are non-homogeneous, simply adding up the years spent in formal education, like is done in average years of education, is analogous with adding apples and oranges. Physical capital, where the physical units are as heterogeneous as different individuals, is accordingly aggregated by the value of individual pieces of equipment. Standard national accounting principles use the book value (or cost) of new equipment to measure, which can also be done with human capital if expenditure on education are available (cost-based human capital). ${ }^{5}$ Whalley and Zhao (2010) make an attempt to include the opportunity costs of education calculate a human-capital measure by combining average years of education with the average wage rate in the population between 1979 and 2008, hence

\footnotetext{
4 Human capital is defined in this paper, in line with the human capital literature, as the qualitative aspect of labor. In other words, the stock of human capital consists of all skills, knowledge and experience that improves the productivity of an individual in the production process. However, very few, if any, countries and time periods have sufficient data to calculate such a comprehensive indicator of human capital. For that reason it is common in the human capital literature to resort to the best possible alternative indicators and to include formal education only.

${ }^{5}$ Alternatively, one could measure the value of both physical and human capital as a net present value of the expected future cash-flow, similarly to securities. In this case human capital would be the net present value of all future expected earnings (income based human capital). The difficulty of estimating future incomes is the main cause while national accounts usually stick to the cost based approach. As result, for comparability, cost-based human capital measures are preferable for growth accounting or growth regressions. Another possible drawback of income based measures is that since real wages reflect changes in technology, income based human capital measures will take up part of the effect of TFP, and thereby lead to biased results.
} 
proxying for foregone earnings. We have found no other information on cost- or income-based measures of human capital for China.

The income based measure of Whalley and Zhao (2010), however, has two drawbacks. First, physical capital is calculated via a cost-based approach making it important for other variables to use the same methodology. Second, income data are often difficult to obtain and, in addition, rarely representative for society as a whole. The method suggested by Judson (2002), which is based on the costs of formal education, is more promising, due to extensive data on government expenditure on education. Being the best available indicator, we estimate a cost-based human-capital stock for the 1922-2010 period based following Judson's formula (2002):

$$
h_{i t}=\sum_{j} d_{i j t} a_{i j t}
$$

where $d_{i j t}$, is public expenditure on education and $a_{i j t}$ is the percentage of the population who have attained level of education $j$ in province $i$ and year $t$. This equation results in the average educational expenditure in year $t$ or the replacement value of a single year of education. But obviously, people might have obtained more (or less) than 1 year of formal education. Therefore, in order to estimate the replacement value of the whole educational stock, following Van Leeuwen and Foldvari (2008), we multiply this by average years of education, educit, and thereby arrive at the total educational expenditure per capita in year $\mathrm{t}$ and province $\mathrm{i}, h_{i t}{ }^{*}$ at replacement value:

$$
h_{i t}^{*}=h_{i t} \cdot e d u c_{i t}(2) \text {. }
$$

We thus need information on expenditure on education by level of education as well as on average years of education. Beginning with the latter, we calculate average years of education in the way suggested by Barro and Lee (2001), as adapted by Foldvari and Van Leeuwen (2009). They start from benchmark years with census data on educational attainment, i.e. 1964, 1982, $1990 .{ }^{6}$ The years inbetween these benchmarks were filled in using the perpetual inventory method proposed by Barro and Lee $(1993 ; 2001)$. However, there is a problem with this method: forward calculation may underestimate the results, while backward calculations will overestimate it with the same amount (see also Portela et al 2004). Therefore, Foldvari and Van Leeuwen (2009) propose to use an average of forward and backward calculations for each individual year. Under the assumption that relative mortality and dropouts remain constant inbetween two census years, taking the average of the prediction form both methods results in unbiased estimates of annual average years of education. For the data before the first and after the last of the censuses, we use the standard method of aggregating by age class and correcting for age-specific mortality (e.g., Van Leeuwen and Foldvari, 2013).

The data on attainment were taken from the 1964 (National Bureau of Statistics of China,

\footnotetext{
${ }^{6}$ We excluded the later census since, due to changing definitions, it would bias the estimates.
} 
Population Statistics Department and Ministry of Public Security, The Third Bureau, 1988), 1982 and 1990 (China National Bureau of Statistics, 1982 and 1990 censuses) censuses. For Taiwan we use the data from Barro and Lee (2010).

The data on educational enrolment from 1907 to 2009 were taken from Li, Qi and Qian (1995), Education Department, Republic of China (1934), the Chinese Education Compile Committee (1946), the National Statistical Bureau (1999) and the National Bureau of Statistics of China (accessed June 2011). Fortunately, the data are quite comprehensive, also including private education. In fact, the data are even subdivided, other than in public and private (the importance of which varied by education level as, for example, many universities were private in the Republican period), in central, provincial, and local government educational facilities. What we did not include is traditional education, i.e. based on the civil examination system. Some schools based on this system lasted well into the $20^{\text {th }}$ century. However, their economic function was very different and their share was small in the period under study. For Taiwan enrolment data are from the Chinese Education Department (1946), Mitchell (1999), and the National Statistics of the Republic of China (Taiwan) (accessed June 2011).

Total population was obtained from Hou (2001), the National Bureau of Statistics of China, Population Statistics Department, the Ministry of Public Security's Third Bureau (1988) and the National Bureau of Statistics of China (accessed June 2011). For Taiwan the total population was obtained from Maddison (2007). The division of the population by age group was taken from the 1953, 1964, 1982, 1990 and 2000 censuses (the last of these was obtained from the National Bureau of Statistics of China, accessed June 2011). For the pre-war period the division is derived from Yin and Qi (2009). For Taiwan the division by age group was obtained from Taiwan's Government Statistics Office (1946), and the Directorate-General of Budget, Accounting and Statistics, Executive Yuan, R.O.C. (Taiwan) (2010).

The results of the provincial average years of modern ${ }^{7}$ education estimates are reported in appendix A. Yet, in order to calculate the cost-based human capital stock at replacement cost, we need, besides average years of education, data on expenditure by educational level as well. These are obtained from the Republic of China's Department of Education (1934), the People's Republic of China's Ministry of Education's Department of Planning (1984), the Editorial Department of China's Education Yearbook (1986), the Chinese Ministry of Finance's Department of General Planning (1989), the Financial Department of the National Education Committee (1990-2010), the Department of Finances of the Guangxi Education Committee (1993), the Hebei Education Department (2009) and the Society Statistics Department

\footnotetext{
${ }^{7}$ This does exclude education in the civil examination system. This means there is a downward bias at the beginning of the $20^{\text {th }}$ century.
} 
As regards data quality the first issue is that for the cost based human capital stock for the modern (non-civil examination) education system we used government expenditure based on government schools and extrapolated that to private education. We are aware of the inherent problems of this method but it is currently the best method available (see e.g. Judson 2002). Second, there may be errors following from biases in the flow data such as enrollment or population numbers. A margin of error is difficult to ascertain. What we tried to do is to calculate alternative estimates of average years of education by adding (or subtracting), 10\% to the available enrolment and population data. This results in a maximum bias of maximum $0.1 \%$. Adding possible bias from census benchmark data and from the use of government expenditure on education, it is fair to say that a random error of ca. $10 \%$ would be the maximum in the $1920 \mathrm{~s}$ and ca. $5 \%$ after the $1950 \mathrm{~s}$.

In showing the results we start with the base estimates of average years of education, compared with some existing estimates, which are presented in Table 1. As one can see, our estimates are closest to those of Barro and Lee (2010), which they based on census data. We do find, however, that our estimates are much higher in the 1960s (1960-1969) than theirs and that growth slowed down afterwards: a pattern in line with total enrolment, which more than doubled during the 1950s. Given that even the poorest of villagers could attain at least three years of basic education, we assume that for the 1960 s 3.6 years is more plausible than 2.4 , especially since the Cultural Revolution between 1966-76 must have had a negative impact on the expansion of formal schooling. Moreover, the estimate from Morrisson and Murtin for the 1920s is largely a conjuncture, as they readily admit. ${ }^{8}$

\section{TABLE 1 ABOUT HERE}

Obviously, to obtain our human capital measure, we must combine average years of education with an indicator of its quality, i.e. educational costs. In Table 2 we report the figures for average years of education and our cost-based human capital measure for several regions in the 1920s and 2000s (Table 2). Although all of them underwent rapid development in both human capital and

\section{TABLE 2 ABOUT HERE}

average years of education, North and Northeast China kept dominating. To summarize, throughout

\footnotetext{
${ }^{8}$ In addition, Morrisson and Murtin (2009) include Chinese traditional education schools (civil examination schools), which we exclude.
} 
the entire period under consideration, human capital in China exhibited a strong regional persistency.

\section{Regional spread of the factors of production}

As noted in the introduction, there seems to be a consensus that TFP growth was the largest in the Eastern provinces. If true, this might be caused by either superior technical efficiency or faster general technological development. In order to decompose TFP in a technical efficiency and a general technological development part, as outlined in Section 1 we need to compare the effect of physical- and human capital in the various provinces. For that reason here we will focus our attention on the spread of physical and human capital in China.

If we look at the stock of physical capital per capita, we find that in the 1950s it was greatest in the Northern provinces. Although the primacy of the North continued, the East and some of the developing provinces, most

\section{MAP 1 ABOUT HERE}

notably Tibet, increased their levels of physical capital considerably, as well (Map 1 and Table 2); thus it seems safe to conclude that average growth of physical capital was considerably higher in the Eastern and developing provinces than elsewhere in China. Indeed, the average annual growth rate of physical capital in the Eastern provinces between 1990 and 2006 was 12.5 per cent, versus 10.6 per cent for China as a whole.

For our cost based measure of human capital, we can see in Map 2 and 3 that it the cost-based human-capital measure (Maps 2 and 3). In general we find that that by the 1920s the North of China had already been the most advanced in terms of human capital. Moreover, the Eastern provinces gained on the North. In this way it, the cost based human capital stock exactly

\section{MAP 2-3 ABOUT HERE}

mirrors the development of physical capital. However, one difference with physical capital is that we find a stagnation (and in some provinces even a decline) of human capital during the Cultural Revolution (see also Deng and Treiman 1997; Caifang and Duyang 2003; Shilei 2010).

These data indicate not only that both physical and human capital displayed considerable persistence over time at the regional level but also that they were especially robust in China's Eastern provinces during the period under study. But does this mean that, being close to a province 
with high levels of human - and physical capital, also increases your chance of having high levels of human-and physical capital? To test this we submit our data to Moran's I are reported in Table 3. Moran's I is a statistics of spatial autocorrelation. A positive value indicates the provinces with higher endowment of human capital are likely to cluster while a zero value refers to a completely random pattern. ${ }^{9}$

$$
I=\frac{N}{\sum_{i} \sum_{j} w_{i j}} \frac{\sum_{i} \sum_{j} w_{i j}\left(X_{i}-\bar{X}\right)\left(X_{j}-\bar{X}\right)}{\sum_{i}\left(X_{i}-\bar{X}\right)^{2}} \text { (3) }
$$

As the formula of Moran's I (equation 3) reflects this statistics is the spatial version of Pearson's linear correlation, where the spatial component is represented by the spatial weights $\left(\mathrm{w}_{\mathrm{ij}}\right)$ in the formula. These are usually the reciprocals of the distance between locations $i$ and $j$. The fact that there is a strong and

\section{TABLE 3 ABOUT HERE}

positive spatial correlation for physical and human capital and per capita GDP suggests that the closer two provinces geographically, the more similar they are in terms of physical and human capital endowments and per capita GDP. These results lend support to our previous observation that regional inequalities persisted in China throughout the twentieth century, despite significant progress in the Eastern provinces.

\section{Technology, technical efficiency and economic growth}

The preceding analysis clearly indicates that physical and human capital accumulation were always more pronounced in the relatively prosperous Eastern provinces. Was this prosperity thus due to a greater amount of 'perspiration'? If this was true, we expect diminishing returns to investment in the factors of production to cause declining economic growth in the future.

In order to answer the question if it were perspiration or inspiration that drove growth, we first estimate the effect of human- and physical-capital accumulation on economic growth in a standard growth accounting framework. We begin our analysis with a standard TFP equation:

$$
\frac{\Delta y_{i t}}{y_{i t}}=\frac{\Delta A_{t}}{A_{t}}+\hat{\alpha} \frac{\Delta k_{i t}}{k_{i t}}+\hat{\beta} \frac{\Delta h_{i t}}{h_{i t}}
$$

\footnotetext{
${ }^{9}$ Moran's I may take negative values ae well, which would mean that similar provinces tend to be far from each other, giving rise to some kind of chessboard pattern. This case is however very unlikely.
} 
where $\frac{\Delta A_{t}}{A_{t}}$ is TFP growth. This standard growth accounting is given in Table 4 for five periods: 1929-1940 (the Republican period), 1950-1966 (the start of socialism), 1966-1977 (the Cultural Revolution), 1978-1993 (the first part of the reform period) and 1994-2006 (the second part of the reform period). These dates signal big difference in economic structure and allow us to test whether the effect of perspiration and inspiration factors on growth change over time. The first of the three sets of rows in below Table provides the factor shares of labor and physical capital;

\section{TABLE 4 ABOUT HERE}

the next set provides the growth of GDP per capita, human capital per capita and physical capital per capita; and the third set provides the TFP growth. TFP growth is negative throughout, and especially so during the period 1950-66. This finding confirms a recently published study indicating negative TFP growth for the late 1990s (Whalley and Zhao 2010). Our findings however, due to the inclusion of the cost-based human capital stock, contradict some other studies including $\mathrm{Hu}$ and Khan (1997) who reports an average TFP growth of 3.9\% in the 1977-1995 period, Bosworth and Collins (2008) who estimates 3.8\% for the period 1978-2004 and Wu (2014) who finds an average TFP growth rate of 1.9\% between 1977 and 2012. For comparison we also report, in the final row of Table 4, the TFP growth estimates based on average years of education rather than the cost based human capital measure, which yield similar results to $\mathrm{Wu}$ (2014) and confirms that using average years of education as a proxy of human capital results higher estimates of the contribution of TFP estimates in growth accounting exercises than with a cost-based human capital measure.

Indeed, our results suggests that, after including human capital, negative or insignificant TFP growth was a structural feature of the Chinese economy throughout the entire twentieth century. This is not so strange since comparable low and negative TFP growth figures are found for Indonesia by Van Zanden and Marks (2012). This does not imply that Chinese technological development is negative. Rather, the reason is TFP consists of two parts, i.e. technical efficiency of human-and physical capital (how efficiently they are used; if one firm need to use more inputs to produce the same amount of output than another, than it is technically less efficient (Farrel 1957).) and general technological development, which allows producers to produce more output using the same amount of inputs than in the previous period.

It is therefore important to decompose the TFP in a technical efficiency part and a technical growth part. The basic idea is that technical efficiency concerns the cross-sectional dimension of aggregate output, that is the differences among different firms, sectors, or in this case provinces, in 
terms of transforming inputs into output at a given level of technology. The empirical literature on measuring technical efficiency is abundant. Where panel data is available, technical efficiency can be measured in a fixed-effect specification (just to mention a few examples: Førsund and Hjalmarsson 1979, Gathon and Perelman 1994, Yu and Wei 2014), but Stochastic Frontier Analysis (Aigner et al 1977) is comparably popular. In this paper we stick to the more traditional fixed-effect panel method.

In order to estimate this panel, if we allow for the technical efficiency differences, then the effect on income of an additional one-percent increase in a factor of production may -- contrary to what is usually assumed in TFP exercises -- vary from province to province. Econometrically this phenomenon is captured by province-specific coefficients. We can thus rewrite the standard TFP analysis while allowing for technical efficiency differences as follows:

$$
\frac{\Delta y_{i t}}{y_{i t}}=\frac{\Delta \theta_{t}}{\theta_{t}}+\alpha_{i} \frac{\Delta k_{i t}}{k_{i t}}+\beta_{i} \frac{\Delta h_{i t}}{h_{i t}}=\frac{\Delta \theta_{t}}{\theta_{t}}+\hat{\alpha} \frac{\Delta k_{i t}}{k_{i t}}+\hat{\beta} \frac{\Delta h_{i t}}{h_{i t}}+\left(\alpha_{i}-\hat{\alpha}\right) \frac{\Delta k_{i t}}{k_{i t}}+\left(\beta_{i}-\hat{\beta}\right) \frac{\Delta h_{i t}}{h_{i t}} \text { (5) }
$$

, where $\theta$ is a time-variant common productivity factor (similar to $A$ in the standard growth accounting in equation (4) but free of the effect of technical-efficiency differences), and $\alpha_{i}$ and $\beta_{\mathrm{i}}$ are the province-specific coefficients. Combining equation (4) and (5) we can show the relationships among TFP growth, general technology growth, and technical efficiency of physical and human capital:

$$
\frac{\Delta A_{t}}{A_{t}}=\frac{\Delta \theta_{t}}{\theta_{t}}+\left(\alpha_{i}-\hat{\alpha}\right) \frac{\Delta k_{i t}}{k_{i t}}+\left(\beta_{i}-\hat{\beta}\right) \frac{\Delta h_{i t}}{h_{i t}}(6)^{10}
$$

It is thus clear that the growth of TFP (A) is not equal to the growth of technical efficiency $(\theta)$ unless there are no regional differences in terms of technical efficiency. Using equation (6) allows us to separate technological development from the effect of technical efficiency. Empirically this is done by allowing the coefficients for physical and human capital to vary over provinces in a fixed effect specification:

${ }^{10}$ The mean of the TFP growth in (6) is not equal to the mean growth rate of $\theta$ (and therefore is not equal to standard TFP accounting) unless: $E\left[\left(\alpha_{i}-\hat{\alpha}\right) \frac{\Delta k_{i t}}{k_{i t}}\right]=E\left[\left(\beta_{i}-\hat{\beta}\right) \frac{\Delta h_{i t}}{h_{i t}}\right]$

Since both sides of above equation can be rewritten as follows:

$$
\begin{gathered}
E\left(\alpha_{i} \frac{\Delta k_{i t}}{k_{i t}}\right)-E\left(\alpha_{i}\right) E\left(\frac{\Delta k_{i t}}{k_{i t}}\right)=\operatorname{Cov}\left(\alpha_{i}, \frac{\Delta k_{i t}}{k_{i t}}\right) \text { and } \\
E\left(\beta_{i} \frac{\Delta h_{i t}}{h_{i t}}\right)-E\left(\beta_{i}\right) E\left(\frac{\Delta h_{i t}}{h_{i t}}\right)=\operatorname{Cov}\left(\beta_{i}, \frac{\Delta h_{i t}}{h_{i t}}\right)
\end{gathered}
$$

we find that the average growth rates of the TFP should only be equal with the mean growth rate of technological development if either the individual coefficient are equal to the growth of the factor, but this is very unlikely since higher physical- or human-capital accumulation may lead to change in the coefficient (this is an obvious deviation from the Cobb-Douglas technology), or if the covariance between the coefficients and the factor growth are the same for both factors, which is quite unlikely. 


$$
\ln y_{i t}=\alpha_{0}+\sum_{i=1}^{25} \alpha_{i} \ln k_{i t}+\sum_{i=1}^{25} \beta_{i} \ln h c_{i t}+\eta_{i}+\tau_{t}+u_{i t}
$$

Where I denotes the provinces ( 25 in total) with $\eta_{i}$ and $\tau_{\mathrm{t}}$ denoting the province and period specific effects with $\mathrm{E}\left(\eta_{\mathrm{i}}\right)=0$. We report the $\alpha$ and $\beta$ coefficients in Table 5. In order to avoid spurious results, even though this is not very

\section{TABLE 5 ABOUT HERE}

likely due to the high number of cross-sectional units in the panel, we also tested if the residuals are stationary. The null hypothesis of unit root was rejected at $1 \%$ by all traditional panel unit root tests. $^{11}$

For better comparability we normalized the coefficient of the province with the highest coefficient to $100 \%$. This yields Figure 1. The region specific coefficients have a considerable spatial dispersion but three striking

\section{FIGURE 1 ABOUT HERE}

patterns emerge.

First, there is a clear negative correlation between the coefficient of physical and human capital. In the relatively prosperous Northeast, Southeast and Central regions the returns to physical capital are by far the highest, while those of human capital are low. In the West on the other hand, the returns on human capital are much higher than on physical capital. This is somewhat expected, since the levels of per capita human capital are highest in the North and lowest in the West (Table 2) and technical efficiency should necessarily reflect the effect of decreasing marginal product and deviations from the Cobb-Douglas technology, a fundamental assumption behind virtually all growth accounting analyses. Nevertheless it seems safe to conclude that those regions that were the most physical-capital (and the least human-capital) intensive experienced the main growth spurts.

Second, if we treat the human capital coefficients from the above regression analysis as indicative of the social returns, then we have to conclude that these outperformed the private returns to a considerable extent. They dropped from ca. 23 per cent in 1950-66 to 0 per cent during the

\footnotetext{
11 The p-values are the following: Levin-Lin-Chu (the residuals are assumed to have a uniform structure, H0: unit-root): 0.0033, Im, Pesharan and Shin (the residuals may have a structure different by provinces, H0: unit-root): 0.000, Hadri test (H0 is stationarity): 0.954
} 
Cultural Revolution, 35 per cent during the reform period and 7 per cent during the period 19942006, whereas during the reform period, when the order of magnitude of the social returns was 35 per cent, that of the private returns ranged from 4 to 12 per cent (Liu 1998; Wei, Tsang, Wu and Chen 1999; Hossain 1997). These figures are in line with Heckman's finding (2005) that the private returns to skills were lower than what one would expect from actual labor productivity. For physical capital, we find average social returns of approximately 50 per cent, close to the figures reported by Heckman. It should be noted that as Brandt et al. (2013) suggests that government ownership contributed to inefficiencies (lower TFP). This finding may have its impact on the regional differences we observe in Table 6 and Figure 1. If Western provinces get a higher share of government investments, this may result in lower returns on capital.

Third, in 1961 general technological development continued on its downward course: a pattern that emerged when we subtracted technical efficiency from TFP growth (Table 4, row 7 and 8). Whereas the technical efficiency of both physical and human capital was consistently negative, at the national level productivity development grew from -1 per cent in 1950-66 to 3 per cent in 1994-2006 (Figure 2). The fact that the decline took place in 1961 may be due in

\section{FIGURE 2 ABOUT HERE}

part to the Great Famine, a consequence of the agricultural reorganizations that were a part of the Great Leap Forward. Another steep downturn occurred during the first years of the Cultural Revolution; after that, however, growth resumed.

\section{Conclusion}

In recent decades there has been an ongoing debate in the literature as to whether China's rapid economic growth is being driven by capital accumulation (perspiration factors) or by TFP growth (inspiration factors). The gap between those on the two sides of the debate is considerable; defenders of the perspiration theory foresee that the growth rate will steadily diminish, as inefficiency in capital accumulation takes its toll. Defenders of the inspiration theory rebut this prediction by citing the many empirical studies that indicate an increase in TFP growth, implying continuous economic growth in the future. Both stances may be true, as far as it goes -- but most of these studies neglect the role of human capital. It has been our purpose in this paper to give human capital its day in court.

In this paper we develop a new dataset for China's human capital as it was distributed at the 
provincial level between 1922 and 2009. We find that as early as the 1920s the provinces of the East and Northeast had already accumulated considerably larger stocks of both human and physical capital than had any of the Western ones. Moreover, their social returns on physical capital were superior, as well. What accounts for this discrepancy is the distinctively regional nature of China's economic structure, a combination of physical capital, human capital and fast growth in the East and of low levels of both human and physical capital and slow growth in the West.

This seemed to suggest that it were especially the factors of production (i.e. perspiration) that drove economic development in the East. However, at the same time, some scholars (e.g. Li 2009) have argued that it was TFP growth that dominated economic development in the East. Our new dataset on human capital, together with existing estimates of physical capital and per capita GDP, permitted us to analyze this hypothesis by performing a TFP analysis for sub-periods. We found a continuously negative TFP growth, suggesting that a decline in productivity is a structural feature of the Chinese economy: a finding in line with the perspiration theory. However, standard growth accounting neglects differences in technical efficiency and leads to bias in the estimated growth rate of TFP, which we find to be significant in the case of China, due to its significant regional differences in physical and human capital accumulation. Having subtracted the effect of technical-efficiency differences across provinces from TFP growth, we find that at the national level general technological development progressed, and at a steadily increasing pace, in the 1990s and 2000s. This finding suggests that, whereas until the reform period China was largely driven by capital accumulation, in subsequent years general technical development assumed an increasingly prominent role, in line with the inspiration theory and, hence, giving hope for future continuous growth.

\section{References}

Aigner, D, Lovell, C, and Schmidt, P, 1977. Formulation and estimation of stochastic frontier production functions. Journal of Econometrics 6 (1), 21-37.

Anderson, T, and Hsiao, C, 1982. Formulation and estimation of dynamic models using panel data. Journal of Econometrics 18 (1), 47-82

Arellano, M, and Bond, S, 1991. Some tests of specification for panel data: Monte Carlo evidence and an application to employment equations. The Review of Economic Studies 58 (2), 277 297.

Bao, S, Chang, G, Sachs, J, and Woo, W, 2002. Geographic factors and China's regional development under market reforms, 1978-1998. China Economic Review 13 (1), 89-111.

Barro, R, and Lee, J-W, 1993. International comparisons of educational attainment. Journal of Monetary Economics 32 (3), 363-394. 
Barro, R, and Lee, J-W, 1996. International measures of schooling years and schooling quality. American Economic Review 86 (2), 219-223.

Barro, R, and Lee, J-W, 2001. International Comparisons of Educational Attainment: Updates and Implications. Oxford Economics Papers 53 (3), 541-63.

Barro, R, and Lee, J-W, 2010. A New Data Set of Educational Attainment in the World, 1950-2010. NBER Working Paper No. 15902.

Blundell, R, and Bond, S, 2000. GMM Estimation with persistent panel data: an application to production functions. Econometric Reviews 19 (3), 321-340.

Bosworth, B, and Collins, S, 2008. Accounting for growth: Comparing China and India. Journal of Economic Perspectives 22 (1), 45-66.

Brandt, L, Tombe, T, and Zhu, X, 2013. Factor market distortions across time, space and sectors in China. Review of Economic Dynamics 16 (1), 39-58.

Cai, F, and Du, Y, 2003. Wenhua dageming dui wuzhi ziben and renli ziben de pohuai. (Destructive Effects of the Cultural Revolution on physical and human capital). China Economic Quarterly 4, 797-98.

China Education Yearbook Editorial Department, 1986. Zhong Guo Jiao yu Nian Jian Di Fang Jiao Yu (China Education Yearbook Local Education 1949-1984). Hunan Education Publishing House, Hunan.

China National Bureau of Statistics. Census 1990. Minnesota Population Center. Integrated Public Use Microdata Series, International: Version 6.1 [Machine-readable database].

(Minneapolis, University of Minnesota, 2011. China Census 1982 and 1990).

Chinese Education Compile Committee, 1946. Di Er Ci Zhong Guo Jiao Yu Nian Jian. (The Second Chinese Education Yearbook). The Commercial Press, Beijing.

Chinese Education Department, 1946. Di San ci Zhong Guo Jiao Yu Nian Jian, Taiwan. (The Third Chinese Education Yearbook). Taiwan.

Chow, G, 1993. Capital formation and economic growth in China. Quarterly Journal of Economics $108(3), 809-842$.

Cohen, D, and Soto, M, 2007. Growth and human capital: Good data, good results. Journal of Economic Growth $12(1), 51-76$.

Collins, S, and Bosworth, B, 1996. Economic growth in East Asia: Accumulation versus assimilation. Brookings Papers on Economic Activity. 2, 135-191.

Deng, Z, and Treiman, D, 1997. The impact of the Cultural Revolution on trends in educational attainment in the People's Republic of China. American Journal of Sociology 103 (2), 391428.

Department of Planning Ministry of Education The people's republic of China, 1984. Zhong Guo 
Jiao Yu Cheng Jiu Tong Ji Zi Liao 1949 - 1983 He 1986 - 1990 (Achievement of Education in China Statistics 1949 - 1983 and (1986 -1990). People's Education Press, China.

Directorate - General of Budget, Accounting and Statistics, Executive Yuan, R.O.C.(Taiwan), 2010. Republic of China Statistics Year book 2009. Directorate - R.O.C. Taiwan, General of Budget, Accounting and Statistics, Executive Yuan.

Education Department, Republic of China, 1934. Di Yi Ci Zhong Guo Jiao Yu Nian Jian (The First Chinese Education Yearbook). Kaiming Press, Shanghai.

Farrell, M, 1957. The Measurement of Productive Efficiency. Journal of the Royal Statistical Society $120(3), 253-290$

Financial Department of National Education Committee, Department of Social Science and Technology Statistics, National Bureau of Statistics of China, 2001. Zhong Guo Jiao Yu Jing Fei Tong Ji Nian Jian 1989 -2010 ( China educational Finance Statistical Yearbook 2000). China Statistics Press, China.

Førsund, F, and Hjalmarsson L, 1979. Frontier Production Functions and Technical Progress: A Study of General Milk Processing in Swedish Dairy Plants. Econometrica 47 (4), 883-900.

Földvári, P, and Van Leeuwen, B, 2009. Average years of education in Hungary: annual estimates 1920-2006. Eastern European Economics 47 (2), 5-20.

Gathon, H, and Perelman, S, 1992. Measuring Technical Efficiency in European Railways: A Panel Data Approach. The Journal of Productivity Analysis 3(1), 135-151.

General Planning Department of Ministry of Finance, 1989. Zhong Guo Cai ZhengTong Ji 1950 1988 (China Finance Statistics1950-1988). China Financial and Economic Publishing House, China.

Guangxi Education Committee Financial Department, 1993. Guang Xi Jiao Yu Jing Fei Tong Ji Zi Liao (Guangxi educational Finance Statistical Data). Guangxi Nationality Publishing House, Guangxi.

Hebei Education Department, 2009. He Bei Sheng Jiao Yu Jing Fei Tong Ji Zi Liao Hui Bian 1949 2008 (Hebei Province Educational Expenditure Statistical Data Assembly 1949-2008). Hebei People Publishing House, Hebei.

Heckman, J, 2005. China's human capital investment. China Economic Review 16 (1), 50-70. Hossain, S, 1997. Making Education in China Equitable and Efficient. Policy Research Working Paper No. 1814. World Bank, Washington, DC.

Hou, Y, 2001. Zhong Guo Ren Kou Shi Di Liu Juan 1910 -1953 (China Population History The Sixth Volume 1910-1953). Fudan University Press, Fudan.

$\mathrm{Hu}, \mathrm{Z}$, and Khan, M, 1997. Why is China growing so fast? IMF Staff Papers. International Monetary Fund, Washington, DC. 
Ju, Y, and Wei, X, 2014. Estimating Regional Technical Efficiency and Its Determinants: Evidence from China’s Provincial Panel Data. Economic and Political Studies 2 (1), 65-87.

Judson, R, 2002. Measuring Human Capital Like Physical Capital: What Does It Tell Us? Bulletin of Economic Research 54 (3), 209-31.

Krugman, P, 1994. The myth of Asia's miracle. Foreign Affairs 73 (6), 62-78.

Krugman, P, 1997. What happened to the Asian miracle? (see http://www.pkarchive.org).

Li, G, Qi, M., and Qian, M, 1995. Zhong Guo Jin Dai Jiao Yu Shi Liao Hui Bian (Collection of Chinese Modern Education information). Shanghai Education Press, Shanghai.

Li, K-W, 2009. China's total factor productivity estimates by region, investment sources and ownership. Economic Systems 33 (3), 213-230.

Li, J, Jorgenson, D, Youjing, Z, and Kuroda, M, 1993. Productivity and economic growth in China, United States and JapanChinese Social Science Press, Beijing.

Liu, Z, 1998. Earnings, Education and Economic Reforms in Urban China. Economic Development and Cultural Change 46 (4), 697-725.

Maddison, A, 2007. Contours of the World Economy 1-2030AD. Oxford University Press, Oxford.

Marquetti, A, and Foley, D, 2011. Extended Penn World Tables: Economic Growth Data on 166 Countries. Downloaded from: http://homepage.newschool.edu/ foleyd/epwt/

Mitchell, B, 1999. International historical statistics: Africa, Asia \& Oceania, 1750-1993. Macmillan, London [etc.].

Morrisson, Ch, and Murtin, F, 2009. The Century of Education. Journal of Human Capital. 3 (1), 142.

National Bureau of Statistics of China. China Statistical yearbook 1996-2010. http://www.stats.gov.cn/english/statisticaldata/yearlydata/ (accessed June 2011).

National Bureau of Statistics of China. Census 2000.

http://www.stats.gov.cn/tjsj/ndsj/renkoupucha/2000pucha/html/t0107.htm (accessed June 2011).

National Bureau of Statistics of China, Population Statistics Department and Ministry of Public Security, The Third Bureau, 1988. Zhong Hua Ren Min Gong He Guo Ren Kou Tong Ji Zi Liao Hui Bian 1949 -1985 ( People of Republic of China Population Statistic Data Collection 1949-1985). China Financial \& Economy Publishing House, Beijing.

National Statistical Bureau, 1999. Comprehensive statistical data and materials on 50 years of New China 1949-1998. Finance and Economic Publishing House, Beijing.

National Statistics Republic of China (Taiwan). Education at the primary, secondary and third level, http://eng.stat.gov.tw/lp.asp?ctNode=2268\&CtUnit=1072\&BaseDSD=36 (accessed June 2011). 
Portela, M, Alessie, R, and Teulings, C, 2004. Measurement Error in Education and Growth Regressions. Tinbergen Institute Discussion Paper, TI 2004-040/3.

Roodman, D, 2009. A Note on the Theme of Too Many Instruments. Oxford Bulletin of Economics and Statistics 71 (1), 135-158.

Shilei, Y, 2010. wenge shiqi de jiaoyu kuozhan. (Expansion of Education During the Cultural Revolution), Twenty First Century Bimonthly 117, 49-58.

Society Statistics Department, National Bureau of Statistics of China, 1994. Zhong Guo She Hui Tong Ji Zi Liao 1993 (China Social Statistics Data 1993). Xinhua Bookstore Beijing Publishing House, Beijing.

Taiwan Government Statistics Office, 1946. Tai Wan Sheng Wu Shi Yi Nian Lai Tong Ji Ti Yao ( 51 Years Data Collection in Taiwan Province). Jinxue Publishing House, Taiwan.

Thomas, V, Wang, Y, and Fan, X, 2000. Measuring Education Inequality: Gini Coefficients of Education. Mimeo, The World Bank, http://econ.worldbank.org/files/1341_wps2525.pdf.

Van Leeuwen, B, amd Foldvari, P, 2008. Human Capital and Economic Growth in Asia 1890-2000: a time-series analysis. Asian Economic Journal 22 (3), 225-240.

Van Leeuwen, B, and Foldvari, P, 2013. Capital accumulation and growth in Central Europe, 19202006. Eastern European Economics 51 (5), 69-93.

Van Zanden, J, and Marks, D, 2012. An economic history of Indonesia, 1800-2012. Routledge, London and New York.

Wang, Y, and Yao, Y, 2003. Sources of China's Economic Growth 1952-1999: incorporating human capital accumulation. China Economic Review 14 (1), 32-52.

Wei, C, 2008. The role of human capital in China's economic development: Review and new evidence. China Economic Review 19 (3), 421-436.

Wei, X, Xu, W, and Chen, L-K, 1999. Education and Earning in Rural China. Education Economics 7 (2), 167-187.

Whalley, J, and Zhao, X, 2010. The Contribution of Human Capital to China's Economic Growth. NBER Working Paper No. 16592.

Wu, H, 2012. An Estimation of China's Employment, Capital Stock, and GDP in 1912-1949. Paper presented at the Asian History Economics Conference, Tokyo.

Wu, H, 2014. China's Growth and Productivity Performance Debate Revisited - Accounting for China's Sources of Growth with a New Data Set. Economics Program Working Paper Series \#14 - 01, The Conference Board.

Wu, Y, 2009. China's Capital Stock Series by Region and Sector. University of Western Australia Discussion Paper 09.02.

Wu, Y, 2004. China's Economic Growth: A Miracle with Chinese characteristics. Routledge Curzon 
Press Limited, London and New York

Yin, M, and Qi, T, 2009. Min Guo Ren Kou Hu Ji Shi Liao Hui Bian 2 (Republic of China Population and Household Historical Data Collection Volume 2). National Library of China Publishing House, Beijing.

Young, A, 1995. The tyranny of numbers: Confronting the statistical realities of the East Asian growth experience. Quarterly Journal of Economics 110 (3), 641-680.

Zhu, X, 2012. Understanding China's Growth: Past, Present, and Future. Journal of Economic Perspectives 26 (4), 103-124.

APPENDIX A ABOUT HERE 
Table 1. Average years of education in China

\begin{tabular}{|c|c|c|c|}
\hline & This text & Barro and Lee & Morrisson and Murtin \\
\hline $1920 \mathrm{~s}$ & 0.4 & & ca. 1 \\
\hline $1930 \mathrm{~s}$ & 0.7 & & \\
\hline $1940 \mathrm{~s}$ & 1.2 & & \\
\hline $1950 \mathrm{~s}$ & 2.2 & 1.9 & \\
\hline $1960 \mathrm{~s}$ & 3.6 & 2.4 & 2.7 \\
\hline $1970 \mathrm{~s}$ & 4.4 & 4.0 & 3.5 \\
\hline $1980 \mathrm{~s}$ & 5.7 & 5.2 & 4.4 \\
\hline $1990 \mathrm{~s}$ & 6.2 & 6.4 & 5.3 \\
\hline $2000 \mathrm{~s}$ & 7.3 & 7.6 & 6.0 \\
\hline
\end{tabular}

Table 2. Human and physical capital in China and Taiwan in the 1920s and 2000s

\begin{tabular}{|c|c|c|c|c|c|}
\hline & $\begin{array}{l}\text { average } \\
\text { years of } \\
\text { education }\end{array}$ & $\begin{array}{l}\text { educational } \\
\text { inequality } \\
\text { (Gini) }\end{array}$ & $\begin{array}{l}\text { human } \\
\text { capital/cap } \\
\text { (1990 GK } \\
\text { dollars) }\end{array}$ & $\begin{array}{l}\text { physical } \\
\text { capital/cap (1990 } \\
\text { GK dollars) }\end{array}$ & $\begin{array}{l}\text { GDP/cap } \\
\text { (1990 GK } \\
\text { dollars) }\end{array}$ \\
\hline & \multicolumn{5}{|c|}{$1920 \mathrm{~s}$} \\
\hline North China & 0.9 & 86.9 & 15.6 & NA & NA \\
\hline Northeast China & 0.8 & 82.0 & 19.2 & NA & NA \\
\hline Southeast China & 0.3 & 94.3 & 3.4 & NA & NA \\
\hline \multicolumn{6}{|l|}{ Central and } \\
\hline Southern China & 0.3 & 94.7 & 2.2 & NA & NA \\
\hline Western China & 0.3 & 94.4 & 2.1 & NA & NA \\
\hline Total China & 0.4 & 93.5 & 2.0 & $465.2^{*}$ & 562.5 \\
\hline Taiwan & \multicolumn{5}{|c|}{$1950 \mathrm{~s}$} \\
\hline North China & 2.7 & 59.4 & 104.3 & 441.6 & 504.0 \\
\hline Northeast China & 3.0 & 49.5 & NA & 747.8 & 902.8 \\
\hline Southeast China & 1.8 & 72.1 & 69.5 & 332.2 & 417.3 \\
\hline Central and & & & & & \\
\hline Southern China & 2.3 & 61.3 & 68.9 & 214.7 & 351.4 \\
\hline Western China & 2.0 & 69.0 & 97.7 & 267.4 & 303.5 \\
\hline
\end{tabular}


Total China

Taiwan

North China

Northeast China

Southeast China

Central and

Southern China

Western China

Total China

Taiwan

\section{2}

4.5

65.2

49.1

8.6

8.2

7.0

7.6

6.3

7.3

10.4

15.7

22.0

20.0

15.3

24.4

16.8

20.1
88.9

NA

391.2

NA

616.4

2000s
$16,029.9$

13,691.9

$13,601.0$

$11,993.1$

$13,323.6$

$23,227.6$

$9,956.6$

*Capital stock in China prior to 1950 taken from Wu (2012). Used with special permission from the author. Note: Northeast China= Beijing, Tianjin, Hebei, Shanxi, Inner Mongolia; Northeast China= Liaoning, Jilin, Heilongjiang; Southeast China= Shanghai, Jiangsu, Zhejiang, Anhui, Fujian, Jiangxi, Shandong; Central and Southern China= Henan, Hubei, Hunan, Guangdong, Guangxi, Hainan; Western China= Chongqing, Sichuan, Guizhou, Yunnan, Shaanxi, Gansu, Qinghai, Ningxia, Xinjiang. Tibet is excluded.

Note: Educational inequality is calculated on the basis of average years of education. For the method see Thomas, Wang and Fan (2000).

Sources: This text and Maddison (2007)

Table 3. Spatial correlation, Moran's I

\begin{tabular}{lccc}
\hline & I & Z & p-value \\
\hline & \multicolumn{3}{c}{$\mathbf{1 9 2 5}$} \\
cost-based human capital & 0.136 & 2.590 & 0.005 \\
K/cap & NA & & \\
GDP/cap & NA &
\end{tabular}

\section{5}

cost-based human capital NA

$\begin{array}{llll}\text { K/cap } & 0.199 & 3.847 & 0.000 \\ \text { GDP/cap } & 0.151 & 2.828 & 0.002\end{array}$

2005

$\begin{array}{llll}\text { cost-based human capital } & 0.108 & 2.163 & 0.015 \\ \text { K/cap } & 0.142 & 2.897 & 0.002 \\ \text { GDP/cap } & 0.206 & 3.535 & 0.000\end{array}$

Note: one tail test 
Table 4. Factor shares and TFP

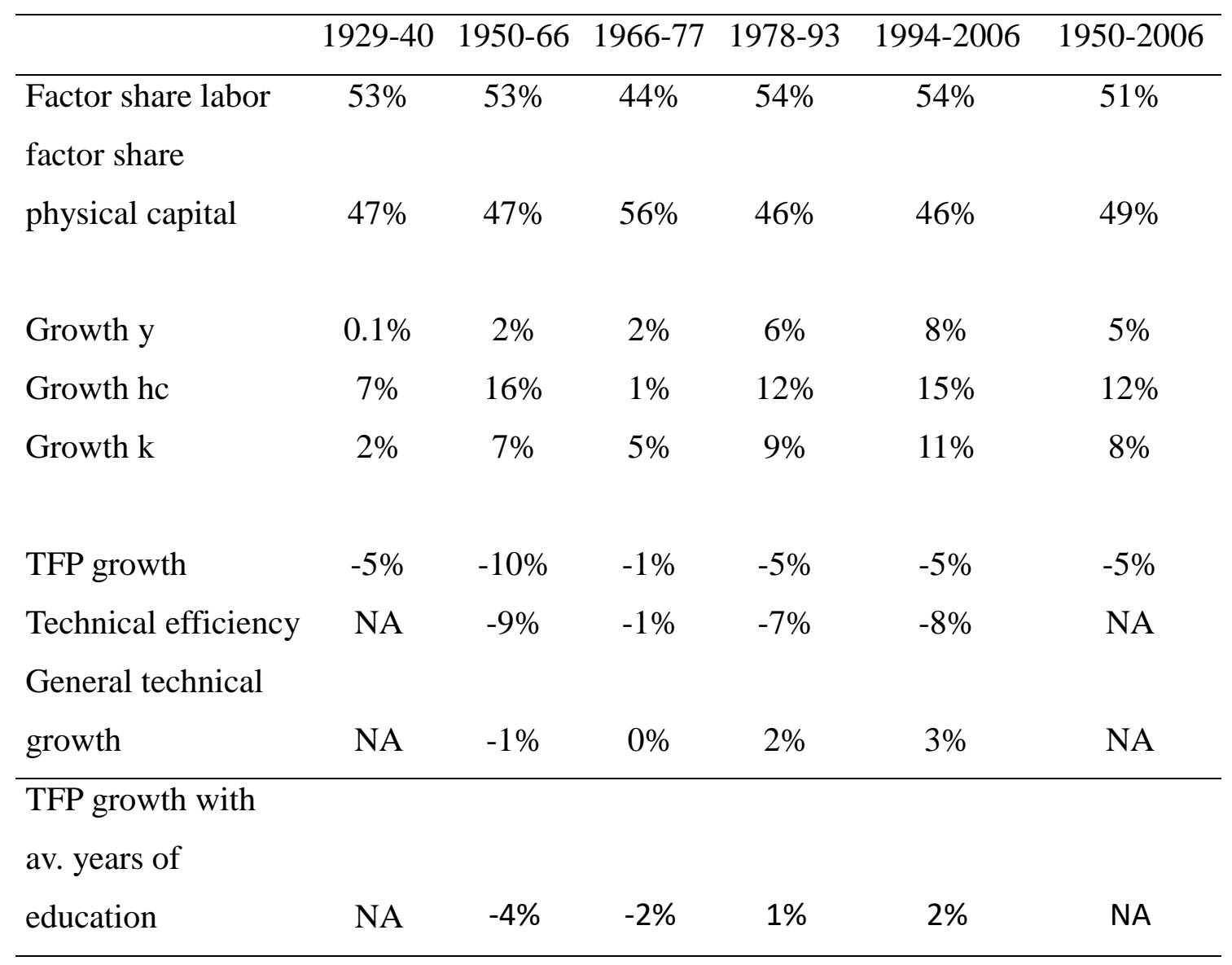

Note: Factor shares from Chow (1993), Li et al. (1997); following Wang and Yao (2003), we assume that the factor share of labor remained unchanged throughout the entire reform period. These estimates are close to the assumption of 0.5 by Brandt et al (2013).

Source: GDP: National Bureau of Statistics of China (accessed June 2011), National Statistical Bureau, 1999; physical capital: $\mathrm{Wu}(2003 ; 2009)$; human capital: this text. 
Table 5. Province specific physical and human capital coefficients, static, fixed effect panel (individual and period specific effects are not reported)

\begin{tabular}{|c|c|c|c|c|c|c|c|c|c|}
\hline & $\begin{array}{l}\log \text { ph } \\
\text { capital }\end{array}$ & & $\begin{array}{l}\log \text { hu } \\
\text { capita }\end{array}$ & & & $\begin{array}{l}\log \mathrm{ph} \\
\text { capita }\end{array}$ & & $\begin{array}{l}\log \text { hu } \\
\text { capital }\end{array}$ & \\
\hline province & coeff. & t-stat & coeff. & t-stat & province & coeff. & t-stat & coeff. & t-stat \\
\hline Hebei & 0.361 & 3.576 & 3.576 & 1.838 & Hubei & 0.420 & 5.063 & 5.063 & $\begin{array}{r}- \\
0.816\end{array}$ \\
\hline Shanxi & 0.510 & 3.564 & 3.564 & 1.115 & Hunan & 0.403 & 3.491 & 3.491 & $\begin{array}{r}- \\
0.109\end{array}$ \\
\hline $\begin{array}{l}\text { Inner } \\
\text { Mongolia }\end{array}$ & 0.115 & 1.145 & 1.145 & 5.413 & Guangdong & 0.077 & 1.593 & 1.593 & 6.289 \\
\hline Liaoning & 0.271 & 2.479 & 2.479 & 1.396 & Guangxi & 0.751 & 5.527 & 5.527 & $\begin{array}{c}- \\
2.267\end{array}$ \\
\hline Jilin & 0.217 & 1.678 & 1.678 & 1.995 & Sichuan & 0.493 & 3.873 & 3.873 & $\begin{array}{c}- \\
0.328\end{array}$ \\
\hline Heilongjiang & 0.722 & 5.387 & 5.387 & $\begin{array}{r}- \\
1.719\end{array}$ & Guizhou & 0.046 & 0.301 & 0.301 & 2.981 \\
\hline Jiangsu & 0.323 & 3.117 & 3.117 & 0.578 & Yunnan & 0.310 & 2.295 & 2.295 & 2.850 \\
\hline Zhejiang & 0.272 & 3.672 & 3.672 & 5.453 & Shaanxi & 0.140 & 1.103 & 1.103 & 4.782 \\
\hline Anhui & 0.269 & 2.594 & 2.594 & 1.436 & Gansu & 0.382 & 2.175 & 2.175 & 3.918 \\
\hline Fujian & 0.524 & 7.700 & 7.700 & 0.204 & Qinghai & 0.183 & 1.032 & 1.032 & 5.516 \\
\hline Jiangxi & 0.353 & 3.071 & 3.071 & 0.706 & Ningxia & 0.151 & 0.886 & 0.886 & 0.464 \\
\hline Shandong & 0.419 & 4.634 & 4.634 & 1.665 & Xinjiang & 0.364 & 3.623 & 3.623 & $\begin{array}{r}- \\
0.337\end{array}$ \\
\hline Henan & 0.382 & 3.775 & 3.775 & 3.187 & & & & & \\
\hline
\end{tabular}


Appendix A: Provincial years of modern education in the population aged 15 years and older in China and Taiwan

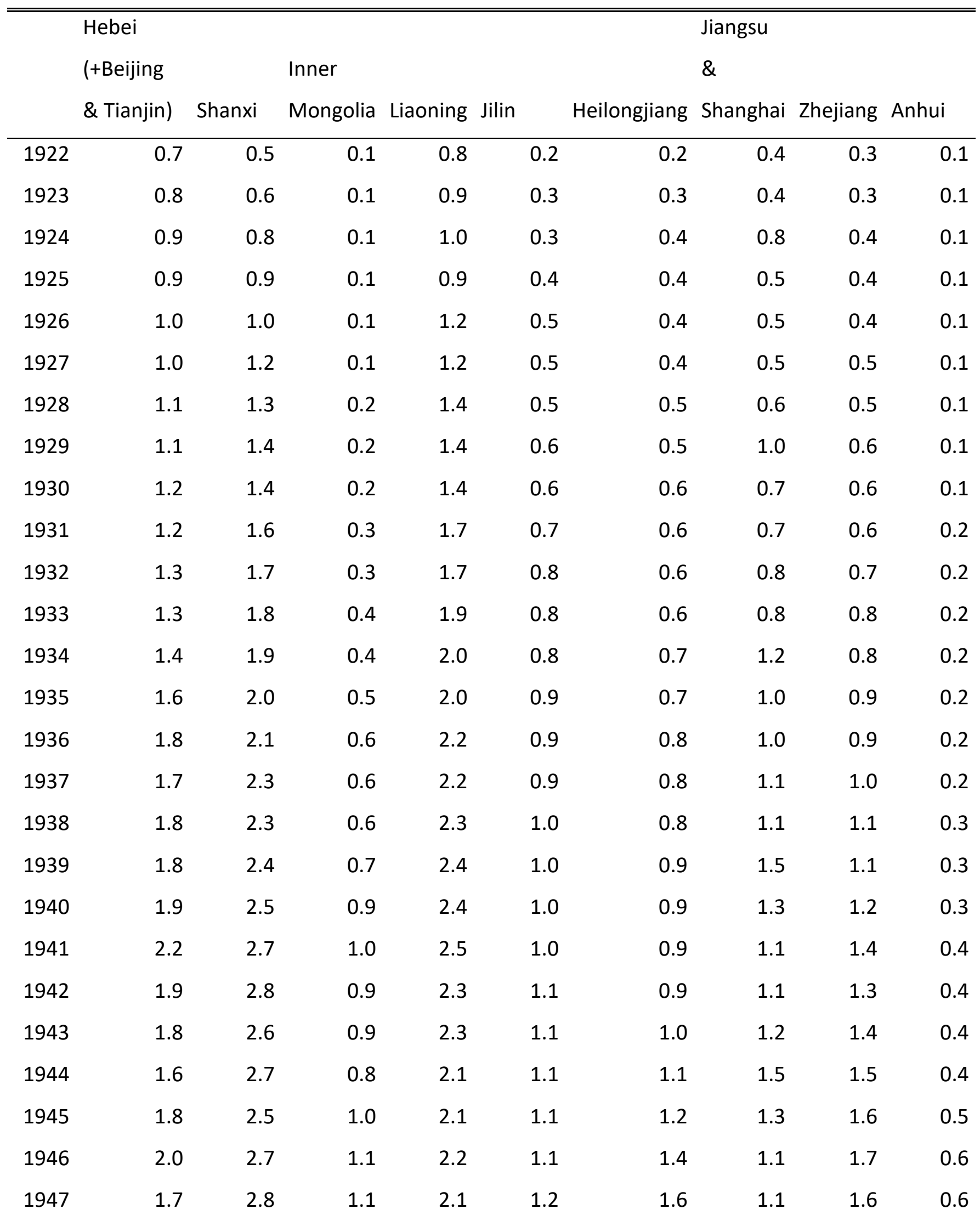


Hebei

Jiangsu

(+Beijing Inner

$\&$

\& Tianjin) Shanxi Mongolia Liaoning Jilin Heilongjiang Shanghai Zhejiang Anhui

\begin{tabular}{|c|c|c|c|c|c|c|c|c|c|}
\hline 1948 & 1.6 & 2.6 & 1.0 & 2.0 & 1.2 & 1.8 & 1.2 & 1.8 & 0.6 \\
\hline 1949 & 1.5 & 2.7 & 1.0 & 1.9 & 1.2 & 2.0 & 1.5 & 1.8 & 0.7 \\
\hline 1950 & 1.7 & 2.7 & 1.2 & 2.2 & 1.2 & 2.4 & 1.5 & 2.1 & 0.8 \\
\hline 1951 & 2.3 & 2.6 & 1.5 & 2.6 & 1.2 & 2.8 & 1.4 & 2.2 & 0.9 \\
\hline 1952 & 2.3 & 2.8 & 1.4 & 2.8 & 1.5 & 2.7 & 1.4 & 2.0 & 0.9 \\
\hline 1953 & 2.4 & 2.8 & 1.3 & 3.0 & 1.9 & 2.7 & 1.5 & 2.1 & 0.9 \\
\hline 1954 & 2.3 & 3.1 & 1.4 & 3.0 & 2.3 & 2.7 & 1.9 & 2.0 & 0.8 \\
\hline 1955 & 2.6 & 3.2 & 1.8 & 3.4 & 2.5 & 3.3 & 2.0 & 2.5 & 0.9 \\
\hline 1956 & 3.3 & 3.2 & 2.2 & 3.9 & 2.8 & 3.7 & 2.1 & 2.9 & 1.4 \\
\hline 1957 & 3.5 & 3.5 & 2.3 & 4.4 & 2.9 & 3.6 & 2.4 & 2.7 & 1.5 \\
\hline 1958 & 3.5 & 3.5 & 2.3 & 4.4 & 3.2 & 3.8 & 2.4 & 2.6 & 1.4 \\
\hline 1959 & 3.4 & 3.7 & 2.3 & 4.1 & 3.3 & 3.5 & 2.7 & 2.6 & 1.3 \\
\hline 1960 & 3.6 & 3.8 & 2.7 & 4.3 & 3.4 & 4.0 & 2.9 & 3.0 & 1.5 \\
\hline 1961 & 4.3 & 3.8 & 3.2 & 4.9 & 3.7 & 4.6 & 3.0 & 3.5 & 2.1 \\
\hline 1962 & 4.5 & 4.1 & 3.2 & 5.4 & 4.0 & 4.5 & 3.4 & 3.3 & 2.2 \\
\hline 1963 & 4.7 & 4.2 & 3.6 & 5.5 & 4.6 & 4.8 & 3.4 & 3.5 & 2.5 \\
\hline 1964 & 4.6 & 4.5 & 3.7 & 5.4 & 4.7 & 4.7 & 3.9 & 3.5 & 2.3 \\
\hline 1965 & 4.7 & 4.7 & 4.2 & 5.5 & 5.0 & 4.9 & 4.2 & 3.7 & 2.5 \\
\hline 1966 & 4.7 & 4.7 & 4.3 & 5.6 & 5.0 & 5.0 & 4.2 & 3.8 & 2.6 \\
\hline 1967 & 4.8 & 4.8 & 4.3 & 5.6 & 5.1 & 5.0 & 4.2 & 3.8 & 2.7 \\
\hline 1968 & 5.0 & 5.0 & 3.5 & 4.3 & 3.8 & 4.3 & 3.1 & 3.4 & 2.5 \\
\hline 1969 & 5.1 & 5.2 & 3.7 & 4.4 & 4.1 & 4.3 & 3.6 & 3.6 & 2.7 \\
\hline 1970 & 5.2 & 5.3 & 4.1 & 4.6 & 4.3 & 4.7 & 3.9 & 4.1 & 3.0 \\
\hline 1971 & 5.2 & 5.3 & 4.4 & 4.7 & 4.4 & 4.9 & 3.8 & 4.0 & 3.0 \\
\hline 1972 & 5.1 & 5.1 & 4.2 & 5.1 & 4.5 & 4.9 & 4.0 & 3.8 & 2.9 \\
\hline 1973 & 5.5 & 5.6 & 4.4 & 5.2 & 4.8 & 5.0 & 4.0 & 4.1 & 3.0 \\
\hline 1974 & 5.5 & 5.6 & 4.6 & 5.3 & 5.1 & 5.1 & 4.4 & 4.3 & 3.2 \\
\hline 1975 & 5.6 & 5.7 & 4.9 & 5.5 & 5.3 & 5.5 & 4.7 & 4.7 & 3.5 \\
\hline 1976 & 5.7 & 5.8 & 5.1 & 5.6 & 5.5 & 5.7 & 4.6 & 4.8 & 3.5 \\
\hline
\end{tabular}


Hebei

Jiangsu

(+Beijing

Inner

$\&$

\& Tianjin) Shanxi Mongolia Liaoning Jilin Heilongjiang Shanghai Zhejiang Anhui

\begin{tabular}{|c|c|c|c|c|c|c|c|c|c|}
\hline 1977 & 5.7 & 5.9 & 5.0 & 6.0 & 5.6 & 5.8 & 4.9 & 4.6 & 3.6 \\
\hline 1978 & 5.9 & 6.1 & 5.2 & 6.2 & 5.8 & 5.8 & 4.9 & 5.0 & 3.8 \\
\hline 1979 & 6.0 & 6.2 & 5.3 & 6.4 & 6.1 & 6.0 & 5.4 & 5.3 & 4.0 \\
\hline 1980 & 6.1 & 6.3 & 5.8 & 6.7 & 6.5 & 6.4 & 5.8 & 5.8 & 4.5 \\
\hline 1981 & 6.0 & 6.2 & 5.9 & 6.5 & 6.6 & 6.6 & 5.8 & 5.7 & 4.6 \\
\hline 1982 & 6.2 & 6.5 & 5.8 & 7.0 & 6.7 & 6.6 & 5.9 & 5.5 & 4.4 \\
\hline 1983 & 6.4 & 6.6 & 6.0 & 7.0 & 6.7 & 6.7 & 6.0 & 5.5 & 4.4 \\
\hline 1984 & 6.5 & 6.7 & 6.1 & 7.1 & 6.8 & 6.7 & 6.0 & 5.5 & 4.5 \\
\hline 1985 & 6.5 & 6.8 & 6.1 & 7.1 & 6.8 & 6.8 & 6.1 & 5.5 & 4.6 \\
\hline 1986 & 6.7 & 6.9 & 6.3 & 7.1 & 6.8 & 6.8 & 6.1 & 5.5 & 4.6 \\
\hline 1987 & 6.8 & 6.9 & 6.4 & 7.1 & 6.8 & 6.8 & 6.2 & 5.4 & 4.6 \\
\hline 1988 & 6.8 & 6.9 & 6.5 & 7.2 & 6.8 & 6.9 & 6.2 & 5.4 & 4.7 \\
\hline 1989 & 6.8 & 7.0 & 6.6 & 7.2 & 6.8 & 6.9 & 6.3 & 5.4 & 4.8 \\
\hline 1990 & 6.9 & 7.0 & 6.7 & 7.2 & 6.8 & 6.9 & 6.3 & 5.4 & 4.8 \\
\hline 1991 & 7.0 & 7.0 & 6.8 & 7.1 & 6.8 & 7.0 & 6.3 & 5.3 & 4.8 \\
\hline 1992 & 7.0 & 7.0 & 7.0 & 7.4 & 6.8 & 7.0 & 6.3 & 5.1 & 4.8 \\
\hline 1993 & 7.0 & 7.1 & 7.1 & 7.4 & 6.8 & 7.0 & 6.3 & 5.3 & 4.9 \\
\hline 1994 & 7.1 & 7.3 & 7.2 & 7.5 & 6.9 & 7.1 & 6.6 & 5.4 & 5.0 \\
\hline 1995 & 7.3 & 7.4 & 7.5 & 7.6 & 7.0 & 7.3 & 6.8 & 5.8 & 5.2 \\
\hline 1996 & 7.4 & 7.4 & 7.6 & 7.5 & 7.1 & 7.4 & 6.8 & 5.7 & 5.2 \\
\hline 1997 & 7.4 & 7.3 & 7.8 & 7.8 & 7.1 & 7.3 & 6.8 & 5.6 & 5.2 \\
\hline 1998 & 7.5 & 7.5 & 7.9 & 7.8 & 7.1 & 7.4 & 6.9 & 5.7 & 5.3 \\
\hline 1999 & 7.7 & 7.7 & 8.1 & 8.0 & 7.3 & 7.5 & 7.2 & 5.9 & 5.5 \\
\hline 2000 & 8.0 & 7.8 & 8.3 & 8.1 & 7.6 & 7.7 & 7.4 & 6.3 & 5.7 \\
\hline 2001 & 8.2 & 7.8 & 8.4 & 8.1 & 7.7 & 7.8 & 7.4 & 6.2 & 5.7 \\
\hline 2002 & 8.3 & 7.8 & 8.7 & 8.4 & 7.7 & 7.8 & 7.5 & 6.1 & 5.7 \\
\hline 2003 & 8.4 & 7.9 & 8.7 & 8.4 & 7.7 & 7.9 & 7.6 & 6.2 & 5.7 \\
\hline 2004 & 8.6 & 8.2 & 9.0 & 8.6 & 7.8 & 8.0 & 7.9 & 6.5 & 5.9 \\
\hline 2005 & 8.7 & 8.3 & 9.1 & 8.8 & 8.0 & 8.1 & 8.1 & 6.8 & 6.2 \\
\hline
\end{tabular}


Hebei

(+Beijing

\begin{tabular}{llllllllll}
\hline 2006 & 8.9 & 8.3 & 9.2 & 8.7 & 8.1 & 8.2 & 8.1 & 6.8 & 6.2 \\
2007 & 8.9 & 8.4 & 9.5 & 9.0 & 8.1 & 8.2 & 8.2 & 6.8 & 6.3 \\
2008 & 8.9 & 8.5 & 9.5 & 8.9 & 8.0 & 8.2 & 8.2 & 6.9 & 6.3 \\
2009 & 9.0 & 8.7 & 9.7 & 9.0 & 8.1 & 8.3 & 8.4 & 7.1 & 6.5 \\
\hline
\end{tabular}

Jiangsu

\&

\begin{tabular}{|c|c|c|c|c|c|c|c|c|c|}
\hline & & & & & & & Guangdong & & $\begin{array}{l}\text { Sichuan \& } \\
\text { Chongqing }\end{array}$ \\
\hline & Fujian & Jiangxi & Shandong & Henan & Hubei & Hunan & \& Hainan & Guangxi & city \\
\hline 1922 & 0.1 & 0.1 & 0.2 & 0.1 & 0.3 & 0.1 & 0.2 & 0.2 & 0.3 \\
\hline 1923 & 0.2 & 0.2 & 0.3 & 0.1 & 0.4 & 0.2 & 0.2 & 0.3 & 0.3 \\
\hline 1924 & 0.2 & 0.2 & 0.3 & 0.1 & 0.4 & 0.2 & 0.3 & 0.3 & 0.3 \\
\hline 1925 & 0.2 & 0.2 & 0.3 & 0.1 & 0.4 & 0.2 & 0.3 & 0.3 & 0.4 \\
\hline 1926 & 0.2 & 0.2 & 0.4 & 0.2 & 0.4 & 0.2 & 0.3 & 0.4 & 0.4 \\
\hline 1927 & 0.2 & 0.2 & 0.4 & 0.2 & 0.4 & 0.2 & 0.3 & 0.4 & 0.4 \\
\hline 1928 & 0.3 & 0.2 & 0.4 & 0.2 & 0.4 & 0.2 & 0.3 & 0.5 & 0.4 \\
\hline 1929 & 0.3 & 0.2 & 0.5 & 0.2 & 0.4 & 0.3 & 0.4 & 0.5 & 0.4 \\
\hline 1930 & 0.3 & 0.3 & 0.5 & 0.2 & 0.4 & 0.3 & 0.4 & 0.5 & 0.4 \\
\hline 1931 & 0.4 & 0.3 & 0.5 & 0.3 & 0.4 & 0.3 & 0.4 & 0.6 & 0.5 \\
\hline 1932 & 0.4 & 0.3 & 0.5 & 0.3 & 0.4 & 0.4 & 0.5 & 0.6 & 0.5 \\
\hline 1933 & 0.5 & 0.3 & 0.5 & 0.3 & 0.4 & 0.4 & 0.5 & 0.7 & 0.5 \\
\hline 1934 & 0.5 & 0.3 & 0.5 & 0.3 & 0.4 & 0.5 & 0.6 & 0.7 & 0.5 \\
\hline 1935 & 0.5 & 0.4 & 0.7 & 0.4 & 0.4 & 0.6 & 0.8 & 0.9 & 0.5 \\
\hline 1936 & 0.5 & 0.4 & 0.7 & 0.4 & 0.4 & 0.6 & 0.9 & 1.0 & 0.5 \\
\hline 1937 & 0.6 & 0.4 & 0.8 & 0.4 & 0.4 & 0.7 & 1.0 & 1.0 & 0.5 \\
\hline 1938 & 0.6 & 0.5 & 0.9 & 0.5 & 0.5 & 0.7 & 1.1 & 1.1 & 0.6 \\
\hline
\end{tabular}


Sichuan \&

Guangdong

Chongqing

Fujian Jiangxi Shandong Henan Hubei Hunan \& Hainan Guangxi city

\begin{tabular}{|c|c|c|c|c|c|c|c|c|c|}
\hline 1939 & 0.7 & 0.5 & 0.8 & 0.5 & 0.5 & 0.7 & 1.2 & 1.2 & 0.6 \\
\hline 1940 & 0.8 & 0.8 & 1.0 & 0.6 & 0.6 & 0.8 & 1.4 & 1.5 & 0.7 \\
\hline 1941 & 1.0 & 0.9 & 1.1 & 0.6 & 0.6 & 0.9 & 1.5 & 1.9 & 0.7 \\
\hline 1942 & 1.0 & 0.9 & 1.1 & 0.7 & 0.6 & 1.1 & 1.6 & 2.0 & 0.8 \\
\hline 1943 & 0.8 & 0.9 & 1.0 & 0.7 & 0.6 & 1.0 & 1.3 & 2.1 & 0.8 \\
\hline 1944 & 1.1 & 1.0 & 0.9 & 0.7 & 0.5 & 1.1 & 1.5 & 2.1 & 0.9 \\
\hline 1945 & 1.2 & 1.3 & 1.0 & 0.8 & 0.7 & 1.3 & 1.6 & 2.4 & 1.0 \\
\hline 1946 & 1.3 & 1.3 & 1.1 & 0.9 & 0.7 & 1.5 & 1.9 & 2.7 & 2.0 \\
\hline 1947 & 1.6 & 1.5 & 1.1 & 1.0 & 0.8 & 1.6 & 2.0 & 2.8 & 1.4 \\
\hline 1948 & 1.4 & 1.5 & 1.1 & 1.0 & 0.9 & 1.6 & 1.8 & 2.8 & 2.3 \\
\hline 1949 & 1.7 & 1.8 & 0.9 & 1.0 & 0.9 & 1.6 & 2.0 & 2.2 & 1.5 \\
\hline 1950 & 1.7 & 2.1 & 0.9 & 1.3 & 1.1 & 2.0 & 2.3 & 2.8 & 1.5 \\
\hline 1951 & 2.0 & 2.2 & 1.1 & 1.4 & 1.2 & 2.1 & 2.7 & 3.2 & 2.5 \\
\hline 1952 & 2.1 & 2.2 & 1.2 & 1.4 & 1.4 & 2.2 & 2.7 & 3.1 & 1.9 \\
\hline 1953 & 1.8 & 1.9 & 1.4 & 1.4 & 1.7 & 2.2 & 2.4 & 3.0 & 2.8 \\
\hline 1954 & 1.9 & 2.0 & 1.2 & 1.3 & 1.7 & 2.1 & 2.4 & 2.3 & 2.1 \\
\hline 1955 & 2.0 & 2.4 & 1.3 & 1.7 & 1.9 & 2.2 & 2.9 & 2.7 & 2.1 \\
\hline 1956 & 2.6 & 2.6 & 1.7 & 2.1 & 2.0 & 2.6 & 3.5 & 3.6 & 3.0 \\
\hline 1957 & 2.8 & 2.8 & 2.0 & 2.3 & 2.2 & 2.9 & 3.7 & 3.8 & 2.5 \\
\hline 1958 & 2.5 & 2.5 & 2.0 & 2.3 & 2.6 & 2.9 & 3.5 & 3.8 & 3.4 \\
\hline 1959 & 2.6 & 2.6 & 1.9 & 2.1 & 2.6 & 2.7 & 3.5 & 3.1 & 2.7 \\
\hline 1960 & 2.7 & 3.0 & 2.0 & 2.4 & 2.9 & 3.0 & 3.9 & 3.4 & 2.8 \\
\hline 1961 & 3.3 & 3.3 & 2.4 & 2.9 & 3.0 & 3.5 & 4.4 & 4.3 & 3.6 \\
\hline 1962 & 3.5 & 3.4 & 2.6 & 3.1 & 3.2 & 3.8 & 4.5 & 4.5 & 3.2 \\
\hline 1963 & 3.4 & 3.4 & 3.0 & 3.3 & 3.5 & 4.2 & 4.3 & 4.7 & 4.0 \\
\hline 1964 & 3.6 & 3.4 & 2.9 & 3.3 & 3.5 & 4.0 & 4.3 & 4.0 & 3.4 \\
\hline 1965 & 3.8 & 3.8 & 3.1 & 3.4 & 3.7 & 4.4 & 4.7 & 4.3 & 3.7 \\
\hline 1966 & 3.9 & 3.9 & 3.2 & 3.4 & 3.8 & 4.4 & 4.8 & 4.4 & 3.7 \\
\hline 1967 & 3.9 & 3.9 & 3.3 & 3.5 & 3.8 & 4.4 & 4.8 & 4.4 & 3.8 \\
\hline
\end{tabular}


Sichuan \&

Guangdong

Chongqing

Fujian Jiangxi Shandong Henan Hubei Hunan \& Hainan Guangxi city

\begin{tabular}{|c|c|c|c|c|c|c|c|c|c|}
\hline 1968 & 3.3 & 3.5 & 2.8 & 2.8 & 3.0 & 3.9 & 3.8 & 4.3 & 4.0 \\
\hline 1969 & 3.6 & 3.8 & 3.1 & 2.9 & 3.0 & 4.0 & 3.9 & 4.0 & 3.6 \\
\hline 1970 & 3.9 & 4.2 & 3.3 & 3.4 & 3.2 & 4.2 & 4.3 & 4.3 & 3.8 \\
\hline 1971 & 3.8 & 4.1 & 3.1 & 3.5 & 3.3 & 4.4 & 4.6 & 4.6 & 4.3 \\
\hline 1972 & 3.9 & 4.1 & 3.3 & 3.5 & 3.5 & 4.4 & 4.7 & 4.9 & 3.9 \\
\hline 1973 & 3.9 & 4.0 & 3.6 & 3.7 & 3.7 & 4.5 & 4.6 & 4.8 & 4.4 \\
\hline 1974 & 4.1 & 4.3 & 3.8 & 3.7 & 3.7 & 4.5 & 4.7 & 4.5 & 4.1 \\
\hline 1975 & 4.4 & 4.7 & 4.0 & 4.0 & 4.0 & 4.8 & 4.9 & 4.8 & 4.1 \\
\hline 1976 & 4.3 & 4.7 & 3.9 & 4.1 & 4.2 & 5.0 & 5.2 & 5.1 & 4.6 \\
\hline 1977 & 4.4 & 4.7 & 4.1 & 4.2 & 4.4 & 5.1 & 5.4 & 5.5 & 4.4 \\
\hline 1978 & 4.7 & 4.7 & 4.4 & 4.3 & 4.7 & 5.4 & 5.4 & 5.4 & 5.1 \\
\hline 1979 & 5.1 & 5.1 & 4.7 & 4.6 & 4.9 & 5.7 & 5.6 & 5.3 & 4.9 \\
\hline 1980 & 5.5 & 5.6 & 5.1 & 5.1 & 5.3 & 6.0 & 5.9 & 5.7 & 5.2 \\
\hline 1981 & 5.3 & 5.6 & 5.0 & 5.2 & 5.6 & 6.1 & 6.2 & 5.9 & 5.6 \\
\hline 1982 & 5.3 & 5.5 & 5.1 & 5.1 & 5.7 & 6.1 & 6.3 & 6.1 & 5.3 \\
\hline 1983 & 5.3 & 5.3 & 5.3 & 5.4 & 5.8 & 6.0 & 6.3 & 6.0 & 5.3 \\
\hline 1984 & 5.3 & 5.3 & 5.3 & 5.4 & 5.9 & 6.1 & 6.3 & 6.0 & 5.3 \\
\hline 1985 & 5.3 & 5.4 & 5.4 & 5.5 & 5.9 & 6.1 & 6.4 & 6.0 & 5.3 \\
\hline 1986 & 5.3 & 5.2 & 5.6 & 5.7 & 6.0 & 6.1 & 6.4 & 6.0 & 5.3 \\
\hline 1987 & 5.2 & 5.1 & 5.7 & 5.9 & 6.0 & 6.0 & 6.4 & 6.0 & 5.3 \\
\hline 1988 & 5.2 & 5.2 & 5.8 & 5.9 & 6.1 & 6.1 & 6.4 & 6.0 & 5.4 \\
\hline 1989 & 5.3 & 5.2 & 5.9 & 6.0 & 6.1 & 6.1 & 6.4 & 6.0 & 5.4 \\
\hline 1990 & 5.2 & 5.1 & 6.0 & 6.1 & 6.1 & 6.1 & 6.4 & 6.0 & 5.5 \\
\hline 1991 & 5.1 & 5.1 & 5.9 & 6.1 & 6.2 & 6.1 & 6.5 & 6.2 & 5.7 \\
\hline 1992 & 5.0 & 5.1 & 5.9 & 6.1 & 6.3 & 6.0 & 6.6 & 6.3 & 5.5 \\
\hline 1993 & 5.1 & 5.0 & 6.0 & 6.1 & 6.3 & 6.1 & 6.6 & 6.2 & 5.8 \\
\hline 1994 & 5.4 & 5.2 & 6.2 & 6.3 & 6.4 & 6.2 & 6.7 & 6.1 & 6.1 \\
\hline 1995 & 5.6 & 5.5 & 6.4 & 6.5 & 6.6 & 6.4 & 6.9 & 6.3 & 5.9 \\
\hline 1996 & 5.5 & 5.5 & 6.3 & 6.5 & 6.7 & 6.5 & 7.0 & 6.5 & 6.0 \\
\hline
\end{tabular}


Sichuan \&

Guangdong

Chongqing

Fujian Jiangxi Shandong Henan Hubei Hunan \& Hainan Guangxi city

\begin{tabular}{llllllllll}
\hline 1997 & 5.5 & 5.4 & 6.4 & 6.5 & 6.7 & 6.4 & 7.2 & 6.7 & 5.9 \\
1998 & 5.6 & 5.3 & 6.6 & 6.5 & 6.8 & 6.5 & 7.2 & 6.6 & 6.1 \\
1999 & 5.9 & 5.6 & 6.9 & 6.8 & 6.9 & 6.7 & 7.4 & 6.6 & 6.5 \\
2000 & 6.1 & 5.8 & 7.2 & 7.1 & 7.1 & 6.9 & 7.6 & 6.8 & 6.4 \\
2001 & 6.2 & 5.8 & 7.1 & 7.1 & 7.2 & 7.0 & 7.7 & 6.8 & 6.5 \\
2002 & 6.2 & 5.8 & 7.2 & 7.1 & 7.3 & 7.0 & 7.8 & 7.1 & 6.4 \\
2003 & 6.3 & 5.7 & 7.4 & 7.1 & 7.4 & 7.1 & 7.9 & 7.0 & 6.7 \\
2004 & 6.5 & 5.9 & 7.7 & 7.4 & 7.5 & 7.3 & 8.0 & 7.0 & 7.1 \\
2005 & 6.7 & 6.2 & 7.9 & 7.6 & 7.6 & 7.5 & 8.0 & 7.2 & 6.9 \\
2006 & 6.7 & 6.2 & 7.8 & 7.7 & 7.7 & 7.5 & 8.2 & 7.2 & 6.9 \\
2007 & 6.8 & 6.2 & 7.9 & 7.7 & 7.8 & 7.5 & 8.5 & 7.5 & 7.0 \\
2008 & 6.8 & 6.2 & 8.0 & 7.7 & 7.8 & 7.5 & 8.6 & 7.3 & 7.1 \\
2009 & 6.9 & 6.3 & 8.3 & 8.0 & 7.8 & 7.6 & 8.7 & 7.4 & 7.7 \\
\hline
\end{tabular}

Guizhou Yunnan Tibet Shaanxi Gansu Qinghai Xinjiang China Taiwan

$\begin{array}{lllllllll}1922 & 0.1 & 0.3 & 0.3 & 0.1 & 0.4 & 0.0 & \mathbf{0 . 3} & \mathbf{0 . 7} \\ 1923 & 0.1 & 0.3 & 0.4 & 0.2 & 0.5 & 0.1 & \mathbf{0 . 3} & \mathbf{0 . 8} \\ 1924 & 0.1 & 0.4 & 0.5 & 0.2 & 0.6 & 0.1 & \mathbf{0 . 4} & \mathbf{0 . 9} \\ 1925 & 0.1 & 0.4 & 0.5 & 0.2 & 0.7 & 0.1 & \mathbf{0 . 4} & \mathbf{1 . 0} \\ 1926 & 0.1 & 0.4 & 0.5 & 0.2 & 0.8 & 0.1 & \mathbf{0 . 4} & \mathbf{1 . 1} \\ 1927 & 0.1 & 0.5 & 0.5 & 0.2 & 0.8 & 0.1 & \mathbf{0 . 4} & \mathbf{1 . 2} \\ 1928 & 0.1 & 0.6 & 0.6 & 0.3 & 0.9 & 0.1 & \mathbf{0 . 5} & \mathbf{1 . 4} \\ 1929 & 0.1 & 0.9 & 0.7 & 0.3 & 0.9 & 0.1 & \mathbf{0 . 5} & \mathbf{1 . 4} \\ 1930 & 0.2 & 1.7 & 0.7 & 0.3 & 1.0 & 0.1 & \mathbf{0 . 6} & \mathbf{1 . 5} \\ 1931 & 0.2 & 0.7 & 0.7 & 0.3 & 1.1 & 0.1 & \mathbf{0 . 6} & \mathbf{1 . 6}\end{array}$




\begin{tabular}{|c|c|c|c|c|c|c|c|c|c|}
\hline & Guizhou & Yunnan & Tibet & Shaanxi & Gansu & Pinghai & בXinjiang & China & "Taiwan \\
\hline 1932 & 0.2 & 0.6 & & 0.7 & 0.3 & 1.1 & 0.1 & 0.6 & 1.7 \\
\hline 1933 & 0.2 & 0.7 & & 0.7 & 0.4 & 1.1 & 0.1 & 0.6 & 1.8 \\
\hline 1934 & 0.2 & 0.9 & & 0.8 & 0.4 & 1.2 & 0.1 & 0.7 & 1.9 \\
\hline 1935 & 0.2 & 1.7 & & 0.8 & 0.3 & 1.1 & 0.1 & 0.8 & 1.9 \\
\hline 1936 & 0.2 & 0.9 & & 0.9 & 0.4 & 1.4 & 0.1 & 0.8 & 2.0 \\
\hline 1937 & 0.2 & 0.8 & & 0.8 & 0.4 & 1.5 & 0.1 & 0.8 & 2.1 \\
\hline 1938 & 0.2 & 0.9 & & 0.9 & 0.4 & 1.3 & 0.1 & 0.9 & 2.2 \\
\hline 1939 & 0.3 & 1.1 & & 1.0 & 0.5 & 1.4 & 0.1 & 1.0 & 2.3 \\
\hline 1940 & 0.3 & 1.8 & & 1.0 & 0.4 & 1.2 & 0.1 & 1.1 & 2.4 \\
\hline 1941 & 0.4 & 1.2 & & 1.1 & 0.5 & 1.5 & 0.1 & 1.1 & 2.6 \\
\hline 1942 & 0.4 & 1.1 & & 1.2 & 0.5 & 1.6 & 0.5 & 1.1 & 2.7 \\
\hline 1943 & 0.4 & 1.3 & & 1.3 & 0.6 & 1.4 & 0.4 & 1.1 & 2.9 \\
\hline 1944 & 0.5 & 1.5 & & 1.5 & 0.6 & 1.6 & 0.4 & 1.2 & 3.0 \\
\hline 1945 & 0.5 & 1.9 & & 1.6 & 0.7 & 1.5 & 0.4 & 1.3 & 3.2 \\
\hline 1946 & 0.6 & 1.5 & & 1.7 & 0.7 & 1.6 & 0.9 & 1.5 & 3.4 \\
\hline 1947 & 0.7 & 1.4 & & 1.8 & 0.8 & 1.8 & 1.2 & 1.4 & 3.6 \\
\hline 1948 & 0.9 & 1.5 & & 1.9 & 0.8 & 1.6 & 1.1 & 1.5 & 3.8 \\
\hline 1949 & 1.0 & 1.7 & & 2.1 & 0.9 & 2.0 & 1.2 & 1.4 & 4.1 \\
\hline 1950 & 0.9 & 2.1 & & 2.3 & 1.0 & 1.6 & 0.8 & 1.6 & 4.2 \\
\hline 1951 & 0.9 & 1.7 & & 2.3 & 1.1 & 1.8 & 1.3 & 1.9 & 4.3 \\
\hline 1952 & 0.9 & 1.5 & & 2.3 & 1.1 & 1.9 & 1.6 & 1.9 & 4.4 \\
\hline 1953 & 0.9 & 1.5 & & 2.3 & 1.1 & 1.7 & 1.6 & 1.9 & 4.5 \\
\hline 1954 & 0.9 & 1.6 & & 2.3 & 1.2 & 2.0 & 1.7 & 1.9 & 4.5 \\
\hline 1955 & 0.9 & 2.1 & & 2.5 & 1.1 & 1.7 & 1.4 & 2.1 & 4.6 \\
\hline 1956 & 1.2 & 1.9 & & 2.7 & 1.2 & 2.0 & 2.0 & 2.5 & 4.6 \\
\hline 1957 & 1.3 & 1.8 & & 2.9 & 1.4 & 2.2 & 2.4 & 2.7 & 4.6 \\
\hline 1958 & 1.3 & 1.8 & & 2.9 & 1.4 & 2.0 & 2.4 & 2.7 & 4.7 \\
\hline 1959 & 1.3 & 1.8 & & 2.9 & 1.5 & 2.3 & 2.5 & 2.6 & 4.7 \\
\hline 1960 & 1.3 & 2.3 & & 3.1 & 1.6 & 2.0 & 2.3 & 2.9 & 4.8 \\
\hline 1961 & 1.9 & 2.2 & & 3.4 & 1.8 & 2.5 & 2.9 & 3.3 & 4.9 \\
\hline 1962 & 2.0 & 2.1 & & 3.5 & 2.1 & 2.6 & 3.3 & 3.5 & 5.0 \\
\hline
\end{tabular}




\begin{tabular}{|c|c|c|c|c|c|c|c|c|c|}
\hline & Guizhou & Yunnan & Tibet & Shaanxi & Gansu & Qinghai & Xinjiang & China & Taiwan \\
\hline 1963 & 2.5 & 2.3 & & 3.7 & 2.4 & 2.8 & 3.8 & 3.7 & 5.1 \\
\hline 1964 & 2.4 & 2.3 & 0.8 & 3.8 & 2.6 & 2.9 & 4.0 & 3.7 & 5.2 \\
\hline 1965 & 2.8 & 2.4 & 1.3 & 3.9 & 2.8 & 3.0 & 4.2 & 3.9 & 5.3 \\
\hline 1966 & 2.8 & 2.5 & 1.2 & 4.0 & 2.8 & 3.1 & 4.3 & 4.0 & 5.4 \\
\hline 1967 & 2.9 & 2.6 & 1.2 & 4.0 & 2.8 & 3.1 & 4.3 & 4.0 & 5.5 \\
\hline 1968 & 2.7 & 2.8 & 0.5 & 3.5 & 2.5 & 2.8 & 3.9 & 3.5 & 5.6 \\
\hline 1969 & 2.8 & 2.9 & 0.6 & 3.8 & 2.9 & 3.0 & 4.1 & 3.7 & 5.8 \\
\hline 1970 & 3.1 & 3.6 & 0.8 & 4.1 & 3.1 & 3.4 & 4.0 & 3.9 & 5.9 \\
\hline 1971 & 2.9 & 3.2 & 1.0 & 4.0 & 2.7 & 3.4 & 4.1 & 4.0 & 6.0 \\
\hline 1972 & 2.7 & 3.0 & 0.9 & 4.1 & 2.7 & 3.0 & 4.1 & 4.0 & 6.1 \\
\hline 1973 & 3.1 & 3.2 & 0.8 & 4.2 & 3.0 & 3.1 & 4.4 & 4.2 & 6.2 \\
\hline 1974 & 3.2 & 3.3 & 0.8 & 4.4 & 3.3 & 3.3 & 4.6 & 4.3 & 6.4 \\
\hline 1975 & 3.4 & 3.9 & 0.9 & 4.8 & 3.4 & 3.6 & 4.6 & 4.5 & 6.5 \\
\hline 1976 & 3.3 & 3.7 & 1.0 & 4.8 & 3.2 & 3.8 & 4.7 & 4.6 & 6.7 \\
\hline 1977 & 3.3 & 3.5 & 1.3 & 4.8 & 3.3 & 3.4 & 4.8 & 4.7 & 6.9 \\
\hline 1978 & 3.4 & 3.7 & 1.4 & 5.0 & 3.6 & 3.8 & 5.1 & 4.9 & 7.0 \\
\hline 1979 & 4.0 & 4.0 & 1.6 & 5.3 & 4.0 & 4.1 & 5.4 & 5.2 & 7.1 \\
\hline 1980 & 4.5 & 4.6 & 1.9 & 5.8 & 4.5 & 4.7 & 5.5 & 5.5 & 7.2 \\
\hline 1981 & 4.4 & 4.3 & 2.0 & 5.7 & 4.3 & 4.9 & 5.7 & 5.6 & 7.4 \\
\hline 1982 & 4.3 & 4.1 & 2.2 & 5.7 & 4.4 & 4.5 & 5.8 & 5.6 & 7.5 \\
\hline 1983 & 4.1 & 4.0 & 2.0 & 5.7 & 4.4 & 4.4 & 5.9 & 5.7 & 7.6 \\
\hline 1984 & 4.1 & 4.1 & 1.8 & 5.8 & 4.4 & 4.4 & 5.9 & 5.7 & 7.7 \\
\hline 1985 & 4.2 & 4.1 & 1.7 & 5.9 & 4.4 & 4.5 & 6.0 & 5.7 & 7.8 \\
\hline 1986 & 4.0 & 4.1 & 1.5 & 5.9 & 4.5 & 4.3 & 6.1 & 5.8 & 7.9 \\
\hline 1987 & 3.9 & 4.1 & 1.3 & 5.9 & 4.5 & 4.2 & 6.2 & 5.8 & 8.0 \\
\hline 1988 & 4.0 & 4.1 & 1.3 & 5.9 & 4.5 & 4.3 & 6.3 & 5.9 & 8.1 \\
\hline 1989 & 4.0 & 4.2 & 1.2 & 6.0 & 4.6 & 4.4 & 6.3 & 5.9 & 8.2 \\
\hline 1990 & 3.9 & 4.2 & 1.1 & 6.0 & 4.6 & 4.2 & 6.4 & 5.9 & 8.3 \\
\hline 1991 & 3.9 & 4.2 & 1.0 & 5.9 & 4.4 & 4.3 & 6.5 & 5.9 & 8.5 \\
\hline 1992 & 3.9 & 4.1 & 0.9 & 5.7 & 4.3 & 4.0 & 6.5 & 5.9 & 8.6 \\
\hline 1993 & 3.9 & 4.2 & 1.0 & 5.8 & 4.4 & 4.2 & 6.7 & 6.0 & 8.7 \\
\hline
\end{tabular}




\begin{tabular}{rrrrrrrrrr}
\hline \hline \multicolumn{2}{c}{ Guizhou } & Yunnan & Tibet & Shaanxi & Gansu & Qinghai & Xinjiang & China & \multicolumn{2}{c}{ Taiwan } \\
\hline 1994 & 4.1 & 4.3 & 1.0 & 6.1 & 4.6 & 4.3 & 7.0 & $\mathbf{6 . 2}$ & $\mathbf{8 . 8}$ \\
1995 & 4.3 & 4.6 & 1.2 & 6.3 & 4.8 & 4.6 & 7.0 & $\mathbf{6 . 3}$ & $\mathbf{8 . 9}$ \\
1996 & 4.3 & 4.6 & 1.3 & 6.2 & 4.6 & 4.6 & 7.1 & $\mathbf{6 . 3}$ & $\mathbf{9 . 1}$ \\
1997 & 4.3 & 4.5 & 1.4 & 6.1 & 4.6 & 4.4 & 7.1 & $\mathbf{6 . 3}$ & $\mathbf{9 . 2}$ \\
1998 & 4.3 & 4.6 & 1.6 & 6.2 & 4.7 & 4.5 & 7.3 & $\mathbf{6 . 4}$ & $\mathbf{9 . 4}$ \\
1999 & 4.5 & 4.7 & 1.7 & 6.5 & 4.9 & 4.7 & 7.6 & $\mathbf{6 . 7}$ & $\mathbf{9 . 5}$ \\
2000 & 4.7 & 5.0 & 1.9 & 6.7 & 5.1 & 4.9 & 7.7 & $\mathbf{6 . 9}$ & $\mathbf{9 . 6}$ \\
2001 & 4.8 & 4.9 & 1.7 & 6.7 & 4.9 & 4.9 & 7.8 & $\mathbf{6 . 9}$ & $\mathbf{9 . 8}$ \\
2002 & 4.7 & 4.9 & 1.8 & 6.6 & 4.9 & 4.7 & 7.8 & $\mathbf{6 . 9}$ & $\mathbf{1 0 . 0}$ \\
2003 & 4.8 & 5.0 & 1.9 & 6.7 & 5.2 & 4.8 & 7.9 & $\mathbf{7 . 0}$ & $\mathbf{1 0 . 2}$ \\
2004 & 5.0 & 5.2 & 2.0 & 7.0 & 5.4 & 4.9 & 8.2 & $\mathbf{7 . 3}$ & $\mathbf{1 0 . 3}$ \\
2005 & 5.3 & 5.4 & 2.1 & 7.2 & 5.5 & 5.1 & 8.2 & $\mathbf{7 . 4}$ & $\mathbf{1 0 . 5}$ \\
2006 & 5.3 & 5.4 & 1.9 & 7.2 & 5.5 & 5.2 & 8.4 & $\mathbf{7 . 5}$ & $\mathbf{1 0 . 6}$ \\
2007 & 5.3 & 5.4 & 2.0 & 7.1 & 5.5 & 5.0 & 8.4 & $\mathbf{7 . 5}$ & $\mathbf{1 0 . 7}$ \\
2008 & 5.3 & 5.5 & 2.1 & 7.2 & 5.9 & 5.2 & 8.5 & $\mathbf{7 . 6}$ & $\mathbf{1 0 . 8}$ \\
2009 & 5.6 & 5.6 & 2.1 & 7.4 & 6.1 & 5.3 & 8.7 & $\mathbf{7 . 8}$ & $\mathbf{1 0 . 9}$ \\
\hline
\end{tabular}


Map 1. Physical capital per capita in 2005 (1990 GK dollars)

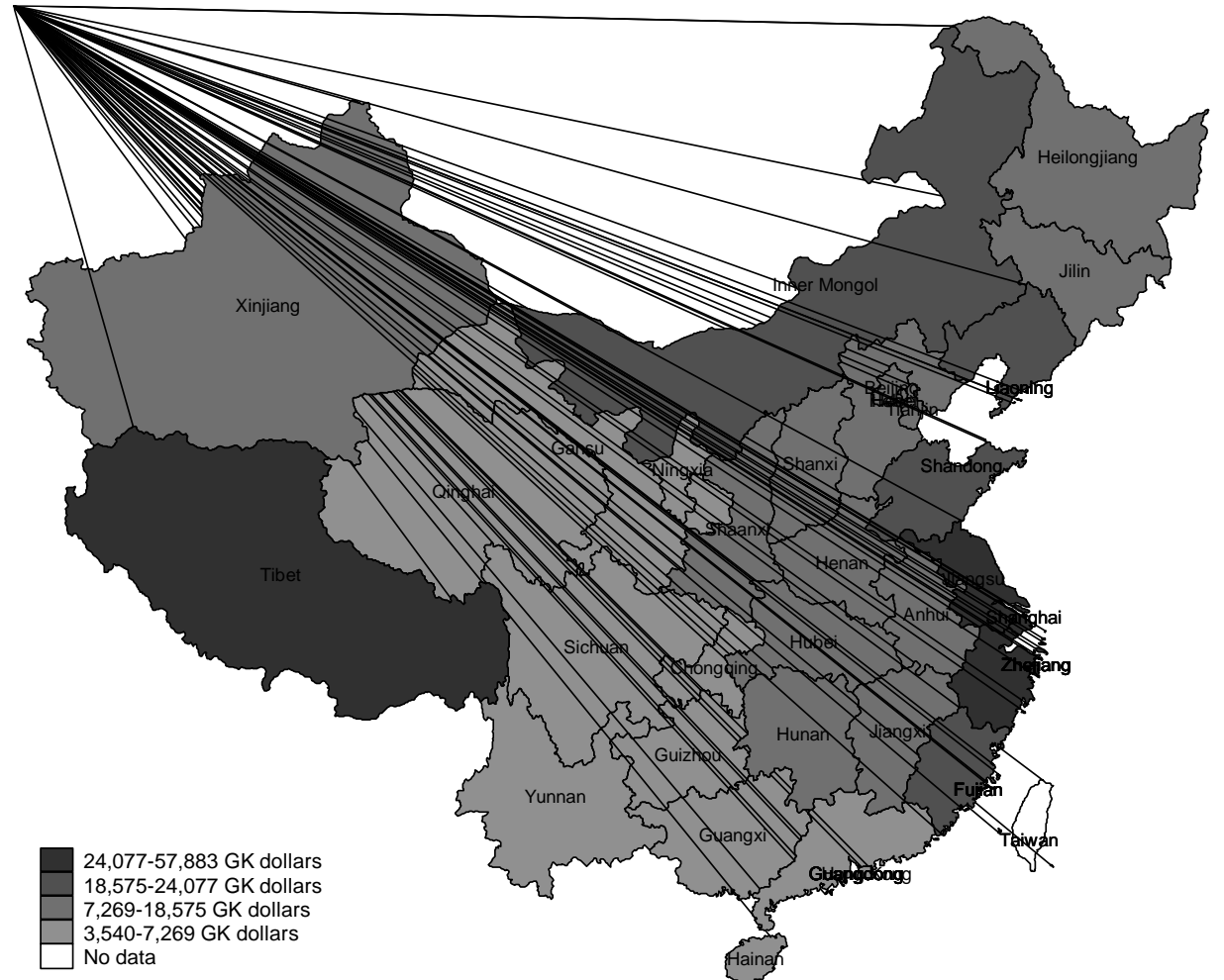

Map 2. Cost-based human-capital measure in 1925 (1990 GK dollars)

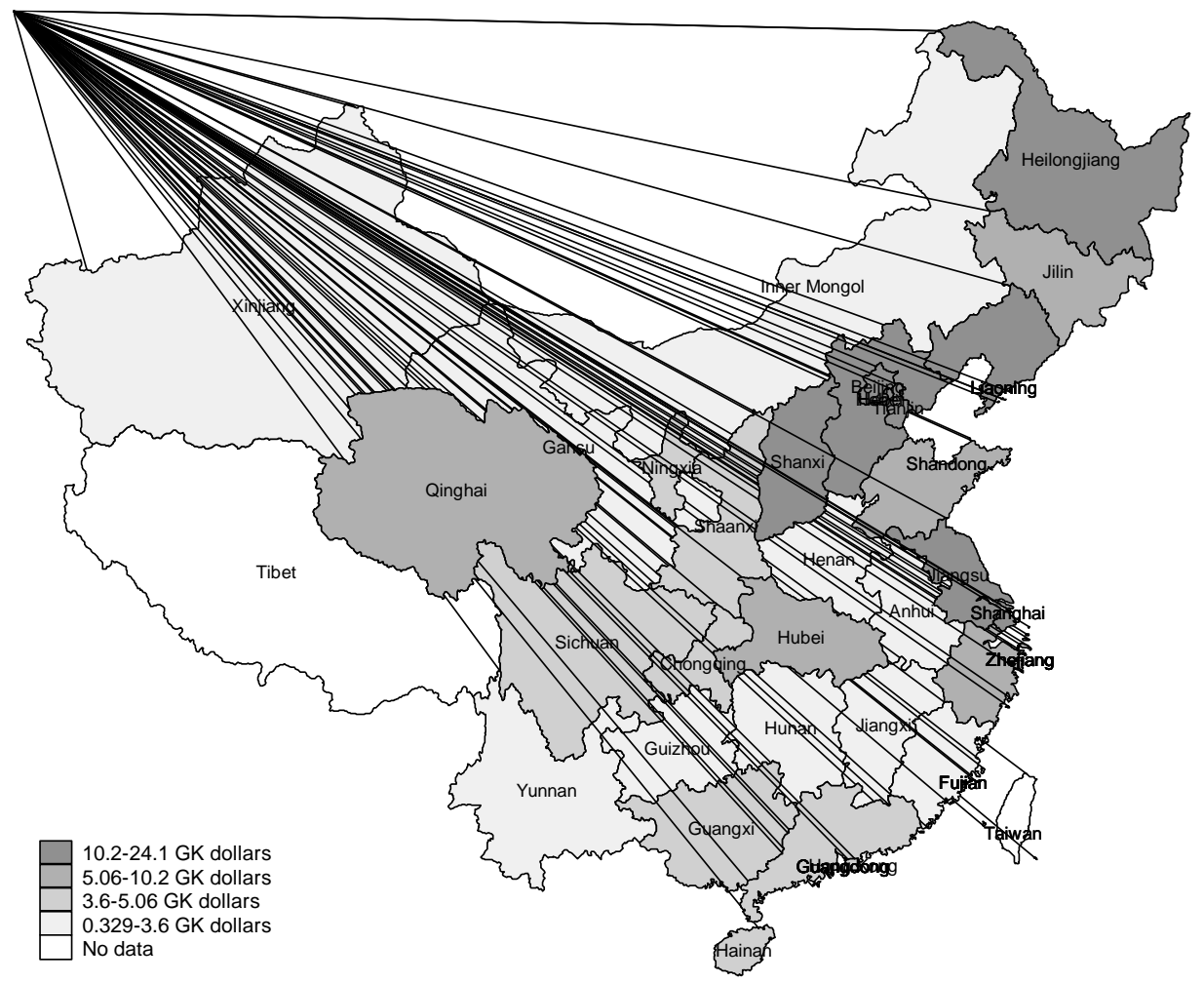


Map 3. Cost-based human capital measure in 2005 (1990 GK dollars)

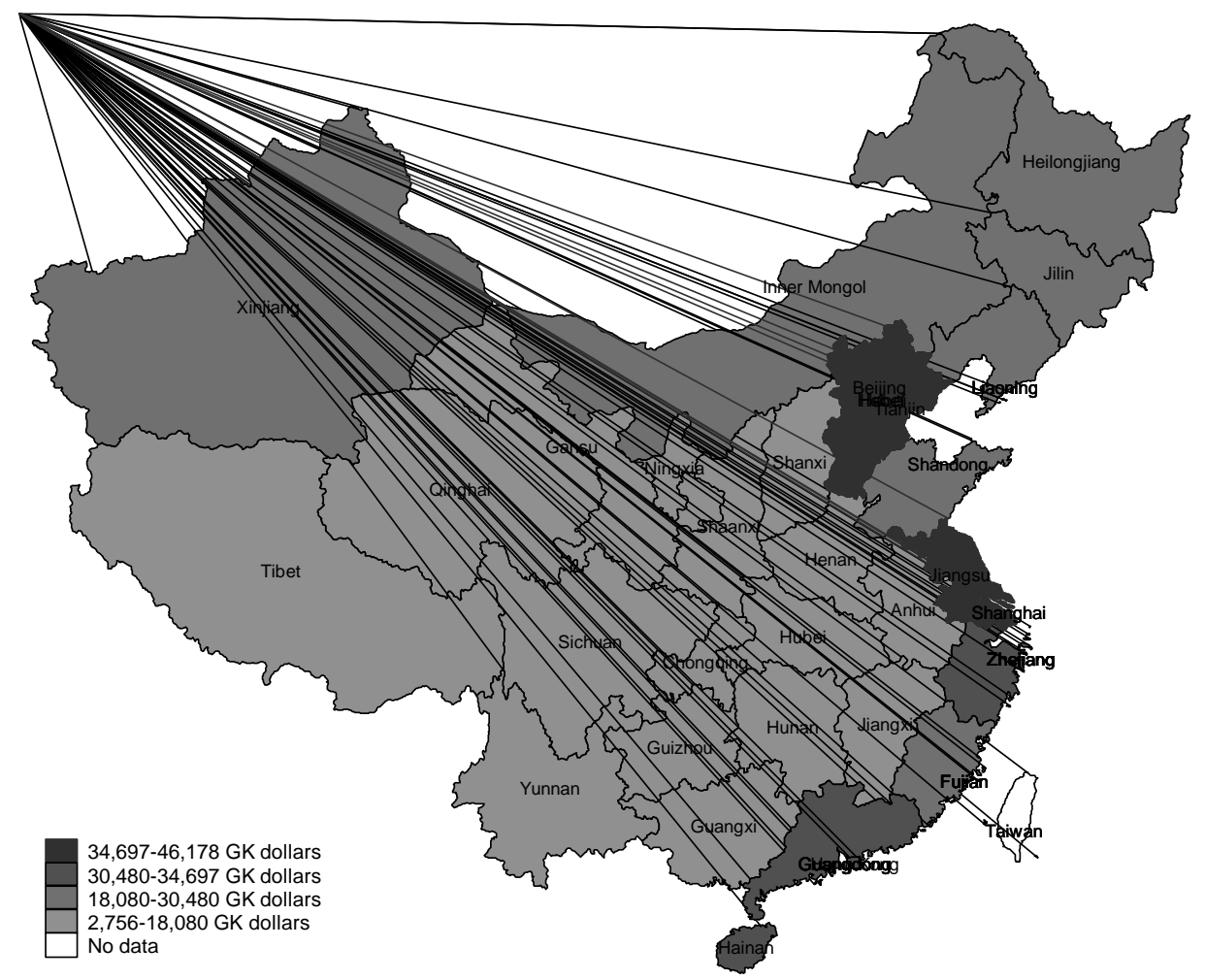

Figure 1. Social returns on physical and human capital by province, 1953-2006.

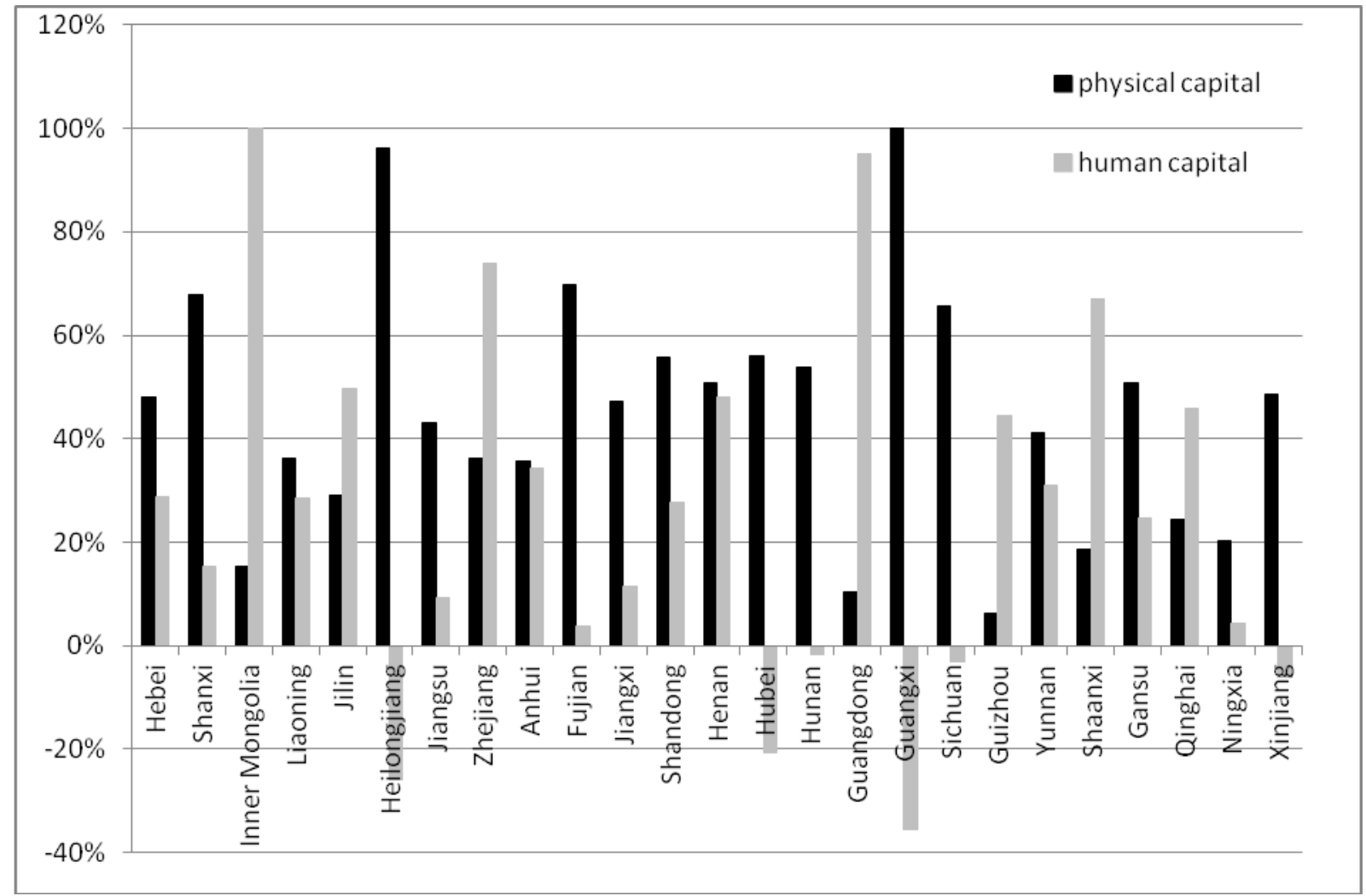


Figure 2. Index of common productivity factor $(\theta)(1953=1)$.

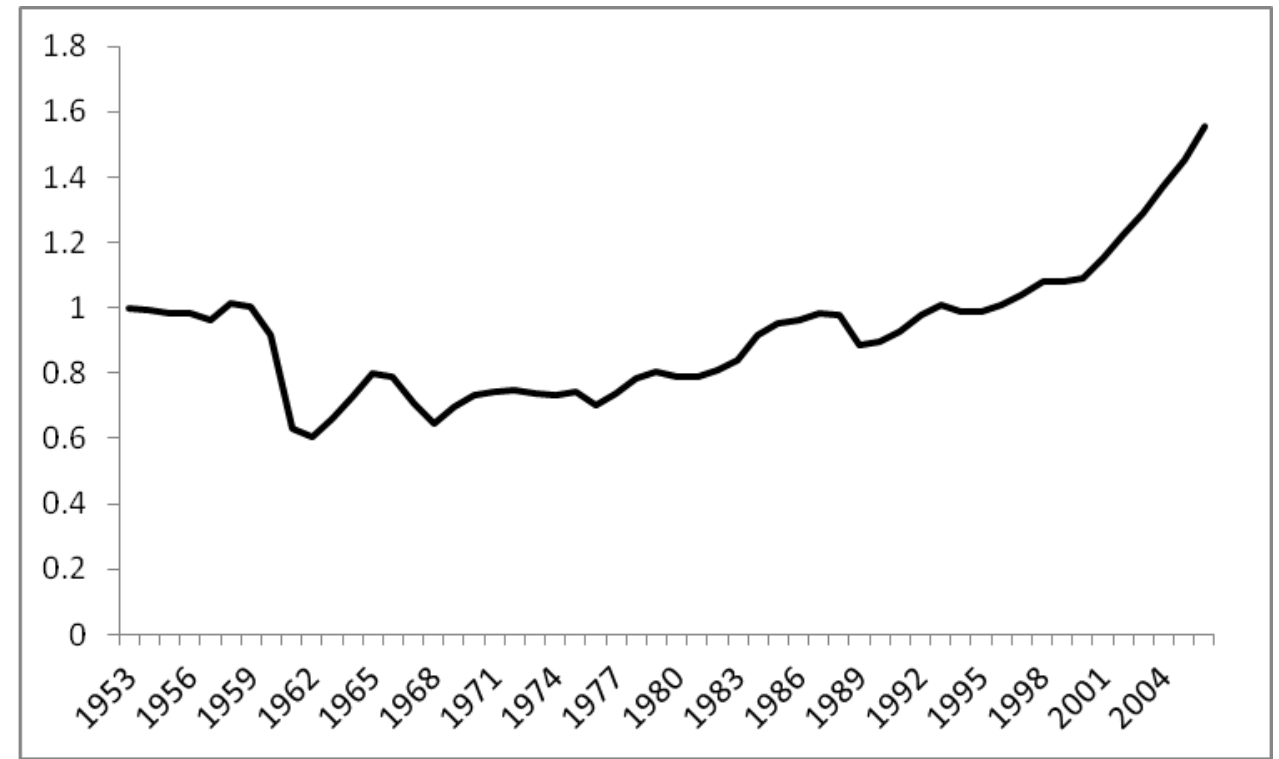

